\title{
Alloy Composition and Critical Temperatures in Type 410 Steel Welds
}

\author{
Predictive formulas for $A_{1}$ and $A_{3}$ temperatures in Type 410 steel welds \\ were developed using the design of experiment approach
}

\author{
BY D. J. STONE, B. T. ALEXANDROV, AND J. A. PENSO
}

\begin{abstract}
The design of experiment (DoE) approach using thermodynamic simulations with ThermoCalc ${ }^{\mathrm{TM}}$ was applied to evaluate the effect of alloy composition on the critical temperatures in Type 410 steels and welding consumables. A predictive equation and predictive diagram for the $A_{1}$ temperature were developed and verified through experimentation and comparison with published data. This was also complemented with the development of a predictive equation for the $\mathrm{A}_{3}$ temperature.

The results of this study show that the combined ASTM and American Welding Society (AWS) compositional specifications for Type 410 materials provide a range of $A_{1}$ temperatures that is significantly wider than the postweld heat treatment (PWHT) temperature range specified by the American Society of Mechanical Engineers (ASME). This creates a potential risk of exceeding the $A_{1}$ temperature during PWHT, resulting in formation of fresh martensite, and can be related to difficulties meeting hardness and toughness requirements for Type 410 welds experienced in industry. Narrowing the ASTM and AWS compositional specifications by introduction of lower limits for all alloying elements, including nitrogen and copper, was identified as a potential solution to this problem.

The predictive tools developed in this study can be applied for selection of welding consumables and base metals, postweld heat treatment (PWHT) temperature selection, and compositional optimization of Type 410 steels and welding consumables.
\end{abstract}

\section{KEYWORDS}

- 410 Steel Welds • Postweld Heat Treatment

- Computational Model-Based Design of Experiment

- Predictive Tools • Materials Selection

\section{Introduction}

ASTM A240 Type 410 martensitic stainless steel is an ironchromium-carbon alloy with balanced carbon and chromium content that provides a useful combination of moderate corrosion resistance, high hardenability and strength, and accept- able toughness (Refs. 1-3). Under equilibrium conditions, martensitic stainless steels are predicted to solidify as delta ferrite, which transforms to austenite upon cooling, followed by decomposition to ferrite and $\mathrm{M}_{23} \mathrm{C}_{6}$ carbides (Ref. 2). However, due to their high hardenability, at normal processing conditions (accelerated or air cooling), the austenite in these steels transforms to martensite. The latter transformation occurs in a temperature range of $200^{\circ} \mathrm{C}$ and is completed above room temperature (Ref. 4). Nonequilibrium solidification, such as that found in welding, leading to partitioning of alloying elements, followed by accelerated cooling through the temperature range of stable delta ferrite may result in retaining of significant amounts of delta ferrite in the final martensitic microstructure (Ref. 2). The optimal combination of hardness, strength, and toughness in martensitic stainless steels is achieved through normalization and a tempering heat treatment (Refs. 1, 4-6).

Compared to austenitic stainless steels, the martensitic stainless grades have significantly higher hardness and strength, and lower cost in combination with good resistance to atmospheric corrosion (Refs. 2-4, 6). Specific advantages of the martensitic grades is their better resistance to sulfur attack and oxidation at higher temperatures, and lower susceptibility to stress corrosion cracking in halide and polyphonic acid-containing environments (Ref. 7). Their application range includes blades for turbines operating in relatively lower temperatures, valves, pumps, shafts, and piping in power generation, oil and gas, and refinery applications. Type 410 steel has found widespread application in refineries as fabricated (welded) components in hydrocrackers, hydrotreaters, and distilling units for crude oil with high sulfur content (Refs. 4, 7).

Type 410 steel is normally welded using consumables with matching composition. However, experience with poor weldability of this steel has been related to formation of hard and brittle martensite in the weld zone, hydrogeninduced cracking, or retention of delta ferrite in the weld metal that negatively affects toughness (Refs. 4, 7). Increasing the weld metal nickel content above $1 \mathrm{wt}-\%$ or using austenitic stainless steel consumables are not considered viable solutions for improved weldability because of compromising the weld metal service properties at high temper- 


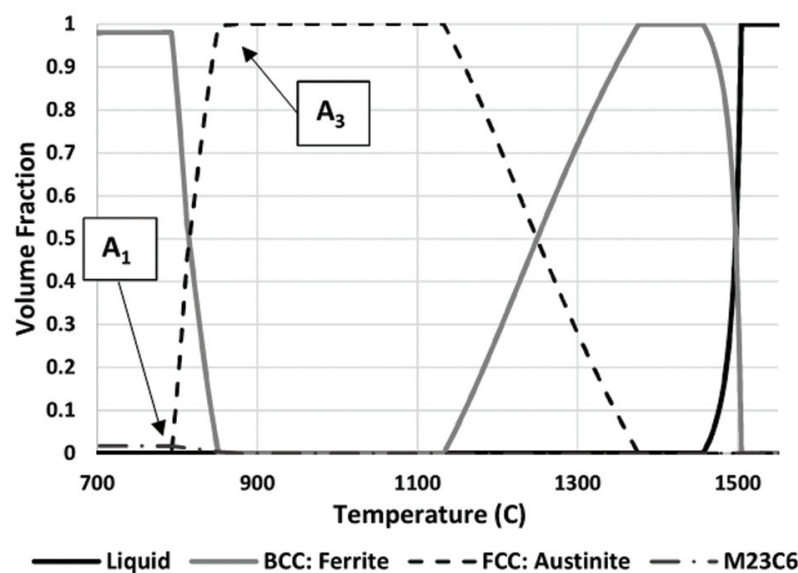

Fig. 1 - Equilibrium phase fraction vs. temperature diagram in DoE Alloy D3 generated using ThermoCalc ${ }^{T M}$.

atures in comparison to the 410 steel base metal (Refs. 5, 7).

The risk of hydrogen-induced cracking in matching filler metal welds of Type 410 steel is reduced by preheating, maintaining proper interpass temperature, and using lowhydrogen welding consumables (Ref. 4). The weld metal and heat-affected zone (HAZ) hardness and toughness are controlled by postweld heat treatment (PWHT) applied to temper the martensitic microstructure and relieve welding residual stresses (Refs. 3, 4, 7). However, problems with inconsistent and unpredictable toughness and hardness, and with meeting the requirements of related American Petroleum Institute (API), NACE, and American Society of Mechanical Engineers (ASME) standards (Refs. 8-11) have been frequently reported by the petrochemical industry.

This study explores the hypothesis that inconsistent hardness and toughness behavior in Type 410 welds can be related to the wide composition ranges of the base metal and matching welding consumables, resulting in wide variations of the $\mathrm{A}_{1}$ temperature and providing potential for random-performing PWHT above this temperature. The effect of this wide composition range on retention of delta ferrite in Type 410 steel welds, as a factor negatively affecting toughness, is addressed in a separate study (Ref. 12).

For Type 410 steel, ASTM A240 specifies compositional ranges for chromium and carbon, and maximum contents of nickel, manganese, and silicon, but does not include molyb-

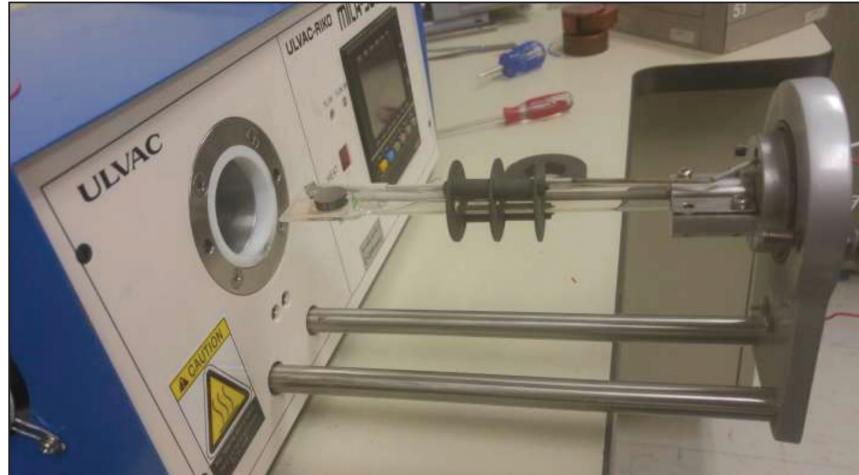

Fig. 2 - Light radiation furnace and test sample setup used in SS DTA experiments.

denum, copper, and nitrogen (Table 1) (Ref. 13). For Type 410 welding filler metals, AWS A5.4-06 and A5.9-17 define the compositional range for chromium and maximum contents for all other specified alloying elements, but do not include nitrogen (Refs. 14, 15). The commercially available wrought alloys and welding filler metals do not utilize this entire compositional space. However, variations in the content of a single specified alloying element and/or presence of small quantities of nonspecified elements could result in significant variations of the $\mathrm{A}_{1}$ temperature. For Type 410 steel welds, ASME B31.3 recommends a PWHT temperature range of $760^{\circ}$ to $800^{\circ} \mathrm{C}$, and ASME Section VIII D1 specifies a minimum PWHT temperature of $760^{\circ} \mathrm{C}$ (Refs. 8, 9). Such a wide PWHT temperature range could potentially overlap with the $A_{1}$ temperature range, resulting in heat treatment above the $A_{1}$ temperature.

$A_{1}$ and $A_{3}$ denote the equilibrium lower and higher critical temperatures in steels. Ferrite (BCC) is the stable equilibrium phase below the $A_{1}$ temperature. Upon exceeding the $A_{1}$ temperature on heating, ferrite gradually transforms to austenite (FCC) with the latter becoming the stable equilibrium phase upon exceeding the $A_{3}$ temperature. The $A_{1}$ and $\mathrm{A}_{3}$ temperatures are determined at equilibrium heating and cooling conditions, such that would allow for completion of all metallurgical reactions occurring at a particular temperature. Faster heating rates, as those experienced in welding or PWHT, would shift the nonequilibrium critical temperatures (denoted correspondingly as $\mathrm{A}_{c 1}$ and $\mathrm{A}_{\mathrm{c} 3}$ ) to higher temperatures. However, the equilibrium critical temperatures $A_{1}$ and $\mathrm{A}_{3}$ are of particular importance for PWHT. Independently of the heating rate, exceeding the $\mathrm{A}_{1}$ temperature during PWHT of Type 410 steel would result in partial reversion of the superheated fresh martensite in the weld metal and

Table 1- ASTM A240, AWS A5.9-93, and A5.4-92 Composition Specifications for Type 410 Steels and Welding Consumables (wt-\%)

\begin{tabular}{ccccccccccc} 
Standard & $\mathrm{C}$ & $\mathrm{Cr}$ & $\mathrm{Ni}$ & $\mathrm{Mo}$ & $\mathrm{Mn}$ & $\mathrm{Si}$ & $\mathrm{P}$ & $\mathrm{S}$ & $\mathrm{Cu}$ & $\mathrm{N}$ \\
\hline AWS A5.5 & 0.12 & $11.0-13.5$ & $0.7^{*}$ & 0.75 & 1.0 & 0.9 & 0.04 & 0.03 & 0.75 \\
AWS A5.9 & 0.12 & $11.0-13.5$ & 0.7 & 0.75 & 0.6 & 0.5 & 0.03 & 0.03 & 0.75 & $=$ \\
ASTM A240 & $0.08-0.15$ & $11.5-13.5$ & 0.75 & - & 1.0 & 1.0 & 0.04 & 0.03 & - \\
Model-Based DoE & $0.01-0.15$ & $11.0-13.5$ & $0-0.75$ & $0-0.75$ & $0-1.0$ & $0-1.0$ & $0-0.04$ & $0-0.03$ & $0-0.75$ & $0-0.04$ \\
\hline
\end{tabular}

*Single values are maxima. 
Table 2 - ThermoCalc ${ }^{\mathrm{TM}}$ Model-Based DOE: Chemical Compositions (wt-\%) and Predicted $A_{1}$ and $A_{3}$ Temperatures

\begin{tabular}{|c|c|c|c|c|c|c|c|c|c|c|}
\hline DOE\# & C & $\mathrm{Cr}$ & $\mathrm{Ni}$ & Mo & $\mathrm{Si}$ & $\mathrm{Mn}$ & $\mathrm{Cu}$ & $\mathrm{N}$ & $\mathrm{Al}$ & A3 \\
\hline DI & 0.01 & 11 & 0.75 & 0.75 & 0 & 1 & 0.75 & 0 & 697 & 816 \\
\hline D2 & 0.01 & 11 & 0 & 0 & 1 & 1 & 0.75 & 0.04 & 752 & 839 \\
\hline D3 & 0.08 & 12.25 & 0.375 & 0.375 & 0.5 & 0.5 & 0.375 & 0.02 & 777 & 878 \\
\hline D4 & 0.01 & 13.5 & 0.75 & 0 & 0 & 0 & 0.75 & 0 & 770 & 954 \\
\hline D5 & 0.15 & 11 & 0.75 & 0 & 1 & 0 & 0.75 & 0.04 & 768 & 902 \\
\hline D6 & 0.15 & 13.5 & 0 & 0.75 & 0 & 1 & 0 & 0 & 803 & 957 \\
\hline D7 & 0.15 & 13.5 & 0 & 0.75 & 1 & 0 & 0 & 0 & 889 & 983 \\
\hline D8 & 0.01 & 11 & 0.75 & 0 & 0 & 0 & 0 & 0.04 & 782 & 821 \\
\hline D9 & 0.01 & 11 & 0 & 0.75 & 0 & 0 & 0 & 0.04 & 839 & 950 \\
\hline DIO & 0.15 & 13.5 & 0.75 & 0.75 & 1 & 1 & 0.75 & 0.04 & 708 & 968 \\
\hline DוI & 0.01 & 11 & 0.75 & 0 & 0 & 1 & 0 & 0 & 725 & 801 \\
\hline $\mathrm{D} 12$ & 0.15 & 13.5 & 0 & 0 & 1 & 1 & 0.75 & 0.04 & 759 & 937 \\
\hline D13 & 0.15 & 11 & 0 & 0 & 1 & 0 & 0 & 0.04 & 829 & 887 \\
\hline D14 & 0.15 & 11 & 0.75 & 0.75 & 1 & 0 & 0 & 0.04 & 808 & 928 \\
\hline D15 & 0.15 & 13.5 & 0 & 0 & 0 & 1 & 0.75 & 0 & 750 & 942 \\
\hline D16 & 0.01 & 13.5 & 0.75 & 0 & 1 & 0 & 0.75 & 0.04 & 780 & 887 \\
\hline DI7 & 0.15 & 11 & 0 & 0.75 & 0 & 1 & 0.75 & 0.04 & 740 & 929 \\
\hline D18 & 0.01 & 13.5 & 0.75 & 0.75 & 0 & 1 & 0 & 0.04 & 749 & 941 \\
\hline D19 & 0.01 & 13.5 & 0.75 & 0.75 & 1 & 1 & 0 & 0 & 784 & 952 \\
\hline D20 & 0.15 & 11 & 0.75 & 0 & 0 & 0 & 0.75 & 0 & 755 & 913 \\
\hline D21 & 0.01 & 11 & 0.75 & 0.75 & 1 & 1 & 0.75 & 0.04 & 712 & 849 \\
\hline $\mathrm{D} 22$ & 0.15 & 11 & 0 & 0 & 0 & 1 & 0 & 0.04 & 766 & 891 \\
\hline D23 & 0.01 & 13.5 & 0.75 & 0 & 0 & 1 & 0.75 & 0.04 & 700 & 799 \\
\hline D24 & 0.15 & 11 & 0.75 & 0 & 1 & 1 & 0.75 & 0 & 703 & 913 \\
\hline D25 & 0.01 & 13.5 & 0 & 0 & 0 & 1 & 0 & 0.04 & 786 & 941 \\
\hline D26 & 0.01 & 11 & 0 & 0.75 & 1 & 0 & 0 & 0 & 879 & 1014 \\
\hline D27 & 0.01 & 11 & 0 & 0 & 0 & 0 & 0.75 & 0.04 & 801 & 830 \\
\hline D28 & 0.15 & 13.5 & 0 & 0.75 & 1 & 1 & 0 & 0.04 & 808 & 955 \\
\hline D29 & 0.01 & 11 & 0 & 0.75 & 1 & 1 & 0 & 0.04 & 807 & 913 \\
\hline D30 & 0.15 & 13.5 & 0 & 0 & 0 & 0 & 0.75 & 0.04 & 806 & 932 \\
\hline D31 & 0.15 & 11 & 0 & 0 & 1 & 1 & 0 & 0 & 790 & 898 \\
\hline D32 & 0.01 & 11 & 0.75 & 0 & 1 & 0 & 0 & 0 & 809 & 885 \\
\hline D33 & 0.01 & 13.5 & 0 & 0 & 0 & 0 & 0 & 0 & 859 & 980 \\
\hline D34 & 0.15 & 13.5 & 0.75 & 0 & 1 & 1 & 0 & 0.04 & 745 & 930 \\
\hline D35 & 0.15 & 13.5 & 0 & 0 & 1 & 0 & 0.75 & 0 & 833 & 942 \\
\hline D36 & 0.15 & 13.5 & 0.75 & 0.75 & 0 & 0 & 0.75 & 0.04 & 767 & 962 \\
\hline D37 & 0.15 & 11 & 0 & 0.75 & 1 & 1 & 0.75 & 0 & 763 & 939 \\
\hline D38 & 0.15 & 11 & 0 & 0.75 & 0 & 0 & 0.75 & 0 & 816 & 939 \\
\hline D39 & 0.15 & 11 & 0.75 & 0.75 & 0 & 0 & 0 & 0 & 797 & 934 \\
\hline D40 & 0.01 & 13.5 & 0 & 0.75 & 1 & 1 & 0.75 & 0 & 805 & 958 \\
\hline D41 & 0.15 & 11 & 0 & 0 & 0 & 0 & 0 & 0 & 824 & 900 \\
\hline D42 & 0.01 & 11 & 0 & 0.75 & 0 & 1 & 0 & 0 & 801 & 925 \\
\hline D43 & 0.15 & 13.5 & 0.75 & 0 & 1 & 0 & 0 & 0 & 817 & 936 \\
\hline D44 & 0.01 & 13.5 & 0.75 & 0.75 & 0 & 0 & 0 & 0 & 834 & 967 \\
\hline D45 & 0.01 & 11 & 0.75 & 0 & 1 & 1 & 0 & 0.04 & 739 & 816 \\
\hline D46 & 0.15 & 13.5 & 0.75 & 0 & 0 & 1 & 0 & 0 & 734 & 935 \\
\hline D47 & 0.01 & 13.5 & 0 & 0 & 1 & 0 & 0 & 0.04 & 864 & 983 \\
\hline D48 & 0.01 & 11 & 0.75 & 0.75 & 0 & 0 & 0.75 & 0.04 & 771 & 834 \\
\hline D49 & 0.15 & 11 & 0.75 & 0.75 & 0 & 1 & 0 & 0.04 & 720 & 925 \\
\hline D50 & 0.01 & 11 & 0.75 & 0.75 & 1 & 0 & 0.75 & 0 & 796 & 920 \\
\hline D51 & 0.15 & 13.5 & 0.75 & 0.75 & 1 & 0 & 0.75 & 0 & 791 & 975 \\
\hline D52 & 0.01 & 13.5 & 0 & 0 & 1 & 1 & 0 & 0 & 822 & 962 \\
\hline D53 & 0.15 & 11 & 0.75 & 0.75 & 1 & 1 & 0 & 0 & 746 & 935 \\
\hline D54 & 0.01 & 13.5 & 0.75 & 0.75 & 1 & 0 & 0 & 0.04 & 838 & 974 \\
\hline D55 & 0.01 & 13.5 & 0 & 0.75 & 0 & 1 & 0.75 & 0.04 & 773 & 945 \\
\hline D56 & 0.01 & 13.5 & 0 & 0.75 & 0 & 0 & 0.75 & 0 & 860 & 974 \\
\hline D57 & 0.01 & 11 & 0 & 0 & 0 & 1 & 0.75 & 0 & 744 & 810 \\
\hline
\end{tabular}


Table 2 - continued

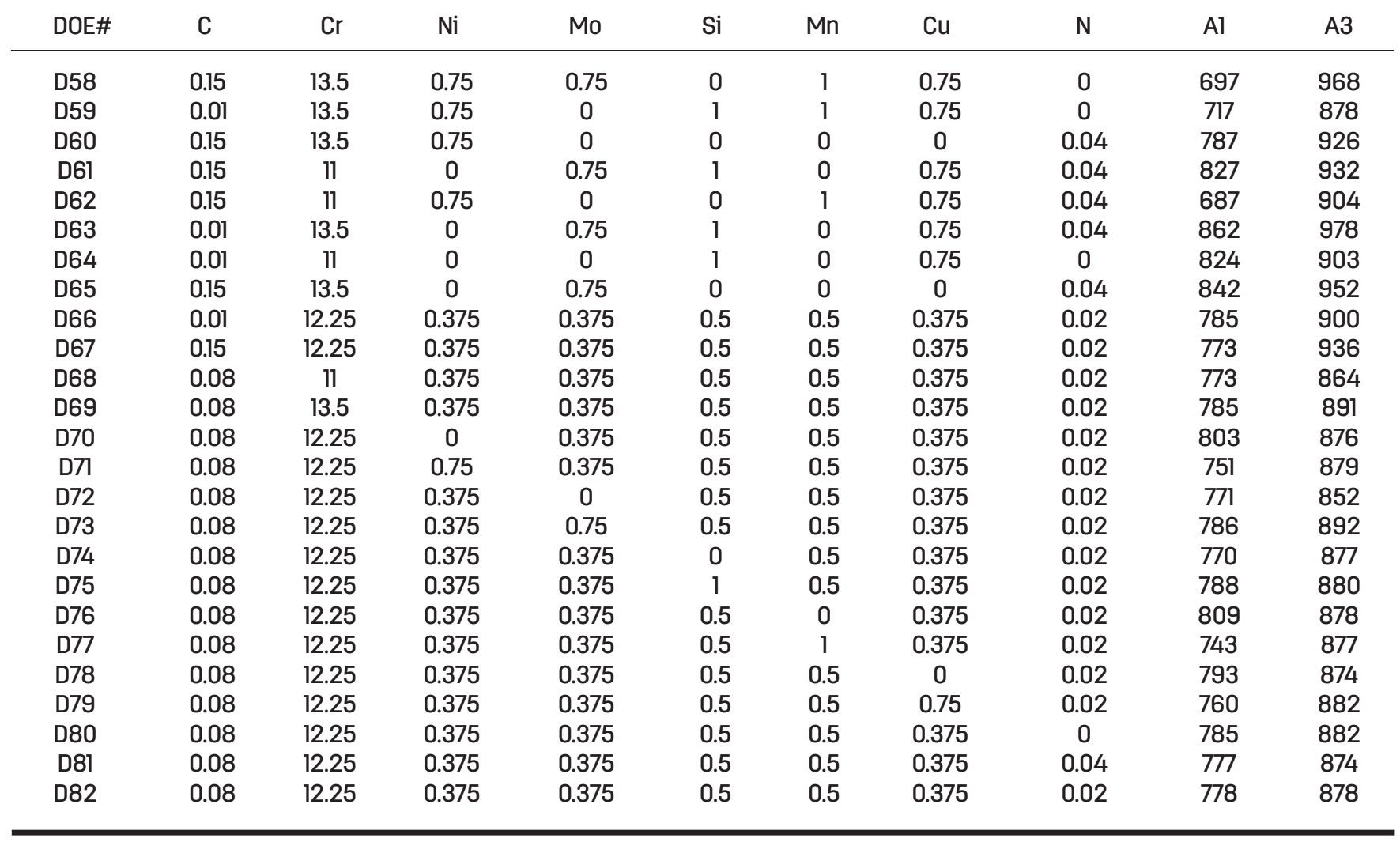

HAZ and/or the tempered martensite in the base metal to austenite. Due to the high hardenability of Type 410 steel, on cooling, the newly formed austenite transforms back to fresh martensite. Unexpectedly high hardness and/or low toughness values have been reported as a result of exceeding the $\mathrm{A}_{1}$ temperature during heat treatment of martensitic stainless steels (Refs. 16-19).

There is insufficient information for $A_{1}$ temperature values in Type 410 steels and on the related effects of alloying elements. This was attributed to difficulties in determination of $\mathrm{A}_{1}$ temperatures related to slower diffusion and transformation kinetics compared to the martensitic transformation (Ref. 4). Rickett et al. experimentally determined $A_{1}$ temperature values between $766^{\circ}$ and $804^{\circ} \mathrm{C}$ in nine steels within the Type 410 compositional range (Ref. 18). Marshall and Farrar reported $\mathrm{A}_{1}$ temperature values of about $800^{\circ} \mathrm{C}$ for Type 410 matching welding consumables (Ref. 4). Based on published data, Gooch et al. developed an empirical equation for the $A_{1}$ temperature in $13 \mathrm{wt}-\%$ chromium steels with carbon content below $0.05 \mathrm{wt}-\%$, stating that the equation should only be used as an approximation and requires further study (Equation 1) (Ref. 5). PWHT in the range of $650^{\circ}$ to $750^{\circ} \mathrm{C}$ has been suggested for Type 410 welds (Refs. 4, 5, 7). However, there is no published information on the effectiveness of PWHT in that temperature range for meeting the hardness and toughness requirements in materials with $\mathrm{A}_{1}$ temperatures closer to $800^{\circ} \mathrm{C}$.

$A C_{1}\left({ }^{\circ} \mathrm{C}\right)=850-1500(C+N)-50 N i-25 M n+25 S i+25 M o$
$+20(C r-10)$
In contrast to Type 410 steel, significant amounts of information has been generated for the $\mathrm{A}_{1}$ temperature in Grade 91 and 92 steels, which represent another class of high-chromium martensitic alloys. Thermodynamic simulations with ThermoCalc ${ }^{\text {TM }}$ (Ref. 19) and model-based design of experiment (DoE) studies based on physical determinations and on computational modeling (Refs. 21-23) were used to determine ranges of variation and generate predictive equations for the $\mathrm{A}_{1}$ temperature.

In this study, similarly, a model-based DoE using thermodynamic simulations with ThermoCalc ${ }^{\mathrm{TM}}$ was applied to quantify the effect of alloying elements on and develop predictive tools for the $\mathrm{A}_{1}$ temperature in Type 410 steel welds and base metals. The latter were verified using experimental measurements with dilatometry and single-sensor differential thermal analysis, and by comparison to published results.

\section{Materials and Procedures}

\section{Model-Based Design of Experiment}

The effect of alloying elements on the $A_{1}$ temperature in Type 410 steel welding consumables and base metals was quantified through development of a model-based DoE within a compositional range that simultaneously covers the corresponding AWS A5.4-06, A5.9-17, and ASTM A240 specifications (see Table 1 ). An eight factor, $1 / 8$ factorial surface response design was selected to generate a range of 


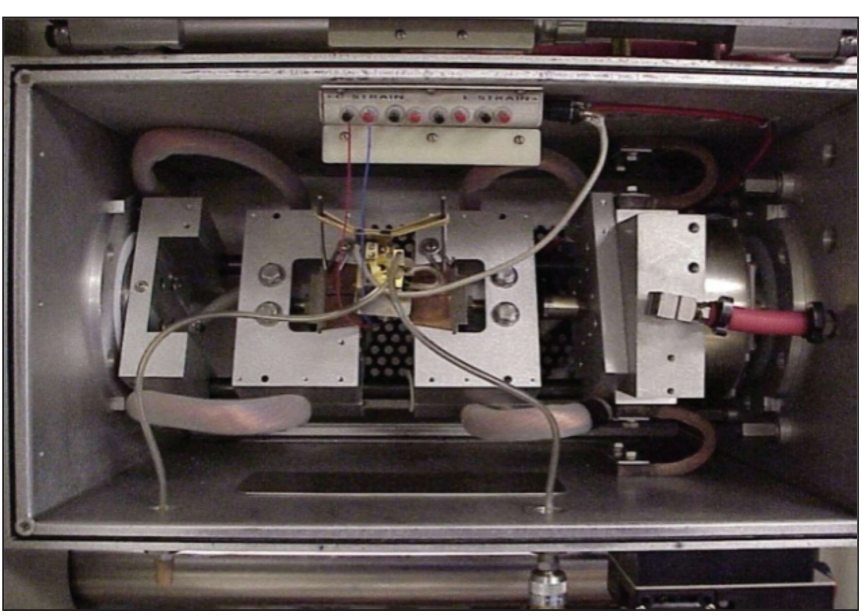

Fig. 3 - Dilatometry experimental setup in the Gleeble $^{T M}$ thermomechanical simulator.

model alloy compositions. The primary alloying elements in Type 410 steel, carbon, chromium, molybdenum, silicon, nickel, copper, and manganese were chosen as DoE factors. Although not specified by ASTM and AWS, nitrogen was also included as a DoE factor. Nitrogen is a strong austenite stabilizer and the goal of including it was to evaluate the effect on the $A_{1}$ temperature of typical trace amounts of nitrogen of up to $0.04 \mathrm{wt}-\%$ found in Type 410 steels.

The model alloys were generated with the MiniTab 17 statistical software using the alloying elements maximum and minimum composition values specified by AWS or ASTM. For elements with no specified minimum, a value of 0 wt-\% was used. For the eight-factor surface response design, 62 theoretical compositions were initially generated to account for linear interactions. The nonlinear interactions were accounted for by generating 20 additional model alloys with the factors set at their mid-range values. This resulted in a DoE with a total of 82 model alloys (Table 2).

The DoE study utilized the thermodynamic software ThermoCalc ${ }^{\mathrm{TM}}$ for prediction of the $\mathrm{A}_{1}$ temperatures in the 82 model alloys. The ThermoCalc ${ }^{\mathrm{TM}}$ simulations were performed using the TCFE8 database with one degree steps within the temperature range between $500^{\circ}$ and $1600^{\circ} \mathrm{C}$. Equilibrium diagrams of phase fraction vs. temperature were developed for each of the 82 model alloys and used to determine the corresponding $\mathrm{A}_{1}$ temperatures - Fig. 1 . The results generated by the model-based DoE were processed using the statistical software MiniTab 17. The processing involved regression analysis as a surface response design using a stepwise method to eliminate insignificant terms and interactions. Predictive formulas for the $\mathrm{A}_{1}$ and $\mathrm{A}_{3}$ temperatures in Type 410 steel weld and base metals were developed. A simplified predictive formula for the $A_{1}$ temperature that excludes the first order interactions terms between alloying elements was also generated.

Using Excel, 2000 random Type 410 steel compositions were generated within the ASTM and AWS specification ranges. The $A_{1}$ temperature values for these compositions were calculated using the simplified $\mathrm{A}_{1}$ prediction formula. The $2000 \mathrm{~A}_{1}$ temperature values were plotted in $25^{\circ} \mathrm{C}$ bins on a predictive diagram using the ferrite and austenite promoting terms of the simplified equation, correspondingly

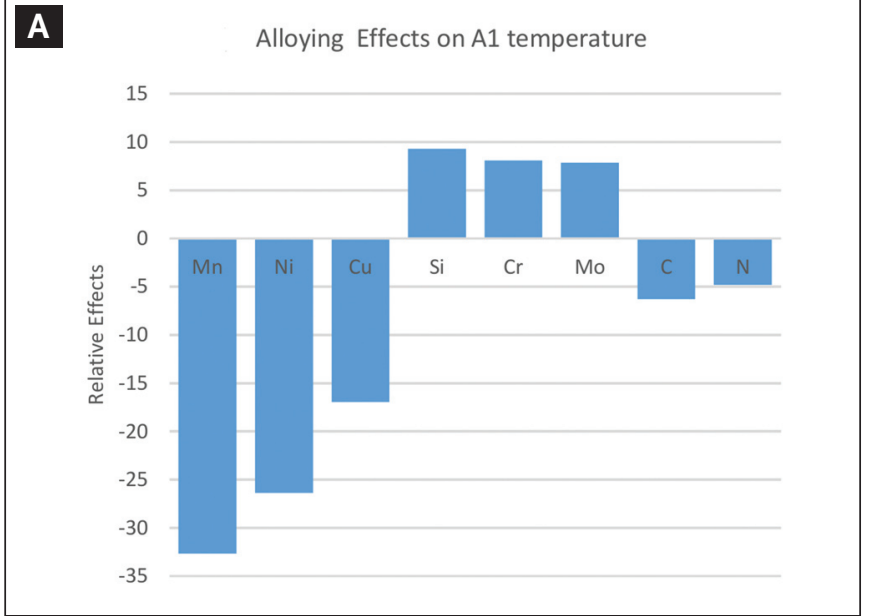

B

Alloying Effects on A3 temperature

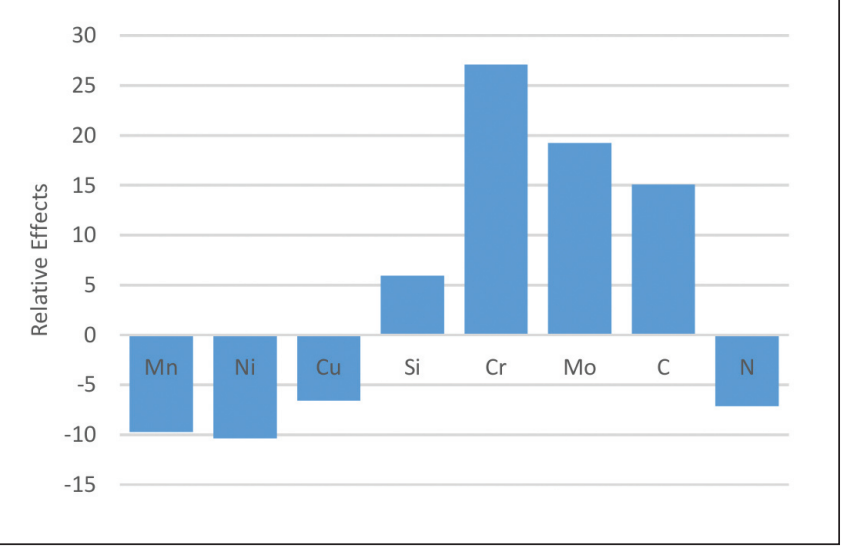

Fig. 4 - Relative effects of alloying elements on the $A_{1}$ (a) and $A_{3}$ (b) temperatures in Type 410 steel base metal and welding consumables.

the chromium and nickel equivalents $\left(\mathrm{Cr}_{\mathrm{Eq}}\right.$ and $\left.\mathrm{Ni}_{\mathrm{Eq}}\right)$, as the diagram axis.

\section{Validation Experiments}

\section{Samples Preparation}

The developed predictive formula for the $\mathrm{A}_{1}$ temperature in Type 410 steel weld and base metals was validated through experimental determination of the $\mathrm{A}_{1}$ temperature in 19 alloys within the standard Type 410 steel compositional range (Table 3). These included five commercially available welding consumables (Alloys A1-A5) and 14 custom-made alloys (B1-B8 and $\mathrm{C} 1-\mathrm{C} 6$ ). The custom alloys were produced by melting charges composed of predetermined fractions of welding consumables (Alloys A1-A5) and 99.9\% pure alloying elements in the form of wire, foil, or powder. The melting was performed using a button-melting apparatus with a copper crucible enclosed within a glass chamber, topped with a gas tungsten arc welding (GTAW) torch. The chamber was purged three consecutive times with $99 \%$ pure argon shielding gas and then held at pressure before melting the material into button samples using a GTAW power supply. All samples were flipped over and 


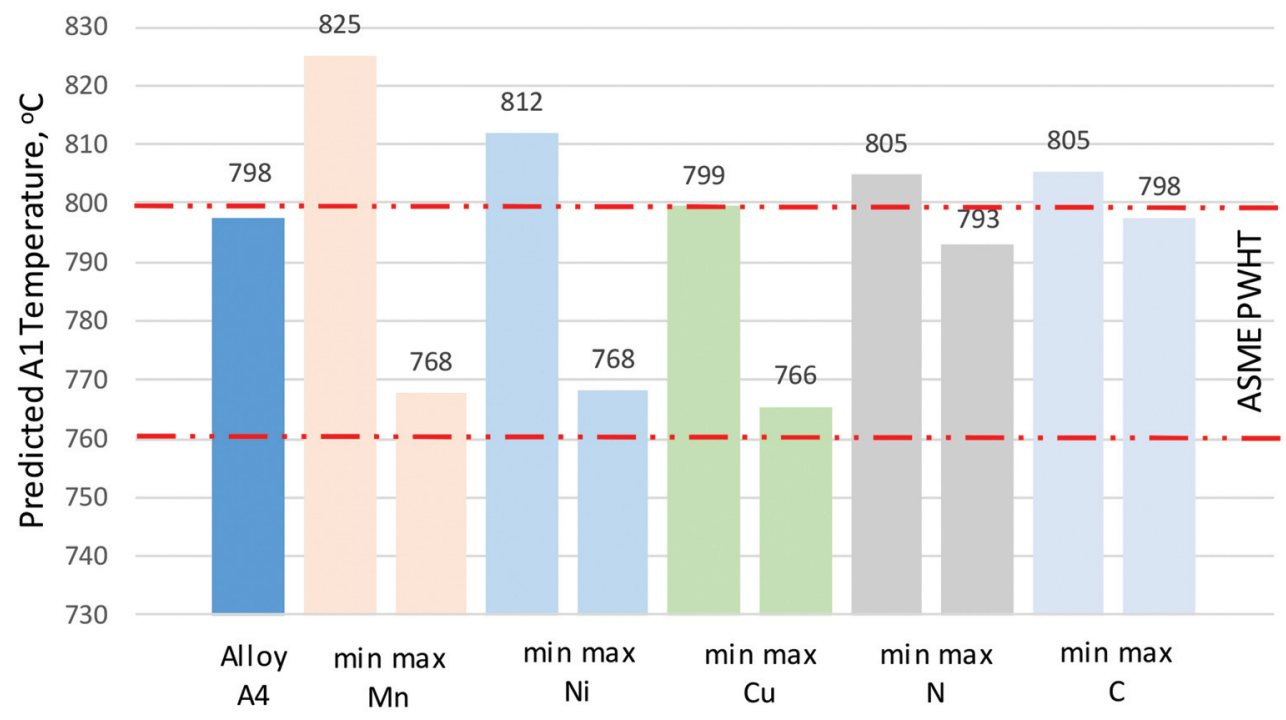

Fig. 5-Effect of varying austenite stabilizing elements within the AWS compositional range on the $A_{l}$ temperature of commercially available ER410 filler metal (Alloy 4).

remelted two times to ensure proper mixing of alloying elements and uniform composition. The chemical composition in all custom-made and commercial alloys was determined using optical emission spectroscopy.

The $\mathrm{A}_{1}$ temperatures in the 19 alloys were determined using dilatometry and/or single-sensor differential thermal analysis (SS DTA). Samples intended for SS DTA were produced by casting into 12 -mm cubes using a square copper mold within the button-melting apparatus and cutting into $12 \times 12 \times 4 \mathrm{~mm}$ samples. Samples intended for dilatometry were cast into 100-mm-long, 5-mm-diameter cylindrical rods within an induction levitation casting device using copper molds. The actual chemical composition of test samples from the 19 alloys was determined using optical emission spectroscopy (see Table 3).

The microstructure in samples of selected alloys was characterized after completion of the phase transformation analysis. Samples were prepared using standard metallography techniques and etched with Vilella's regent, followed by examination under a light optical microscope.

Table 3 - Chemical Composition of Commercial (Al-A5) and Custom Made (BI-B8, Cl-C6) Alloys Used in Validation Experiments (wt-\%)

\begin{tabular}{cllllllllll} 
Alloy \# & $\mathrm{C}$ & $\mathrm{Cr}$ & $\mathrm{Ni}$ & $\mathrm{Mo}$ & $\mathrm{Mn}$ & $\mathrm{Si}$ & $\mathrm{P}$ & $\mathrm{S}$ & $\mathrm{N}$ & $\mathrm{Cu}$ \\
\hline A1 & 0.105 & 11.8 & 0.13 & 0.018 & 0.54 & 0.37 & 0.03 & 0.03 & 0.021 & 0.18 \\
A2 & 0.08 & 12.2 & 0.2 & 0.02 & 0.4 & 0.3 & 0.02 & 0.01 & 0.04 & 0.03 \\
A3 & 0.11 & 12.27 & 0.16 & 0.02 & 0.45 & 0.33 & 0.02 & 0.001 & 0.037 & 0.08 \\
A4 & 0.12 & 12.36 & 0.23 & 0.04 & 0.48 & 0.47 & 0.02 & 0.001 & 0.012 & 0.04 \\
A5 & 0.13 & 12.3 & 0.17 & 0 & 0.82 & 0.25 & 0.015 & 0.006 & 0.04 & 0.01 \\
B1 & 0.1 & 12.3 & 0.108 & 0.241 & 0.674 & 0.359 & 0.03 & 0.003 & 0.00805 & 0.549 \\
B2 & 0.078 & 12.43 & 0.793 & 0.333 & 0.33 & 0.24 & 0.018 & 0.004 & 0.017 & 0.0217 \\
B3 & 0.08 & 13.67 & 0.276 & 0.141 & 0.396 & 0.286 & 0.0175 & 0.003 & 0.018 & 0.222 \\
B4 & 0.113 & 13.32 & 0.634 & 0.0153 & 0.81 & 0.612 & 0.0166 & 0.00339 & 0.018 & 0.206 \\
B5 & 0.105 & 11.25 & 0.334 & 0.243 & 0.622 & 0.281 & 0.0166 & 0.00323 & 0.016 & 0.467 \\
B6 & 0.0853 & 11.18 & 0.476 & 0.0132 & 0.38 & 0.749 & 0.0138 & 0.00325 & 0.015 & 0.501 \\
B7 & 0.115 & 13.77 & 0.29 & 0.0177 & 0.472 & 0.695 & 0.0193 & 0.00379 & 0.016 & 0.2 \\
B8 & 0.0904 & 12.21 & 0.421 & 0.0915 & 0.547 & 0.651 & 0.0208 & 0.00437 & 0.016 & 0.178 \\
C1 & 0.14 & 11.48 & 0.24 & 0.019 & 1.168 & 1.74 & 0.014 & 0.0043 & 0.0175 & 0.909 \\
C2 & 0.148 & 12.64 & 0.231 & 0.458 & 0.797 & 0.583 & 0.023 & 0.0039 & 0.0179 & 0.085 \\
C3 & 0.128 & 11.43 & 0.787 & 0.703 & 0.35 & 0.969 & 0.015 & 0.0032 & 0.0152 & 0.846 \\
C4 & 0.138 & 12.85 & 0.546 & 0.035 & 0.489 & 0.559 & 0.025 & 0.0038 & 0.0168 & 0.086 \\
C5 & 0.225 & 14.45 & 0.35 & 0.796 & 0.529 & 0.703 & 0.019 & 0.0032 & 0.0189 & 0.661 \\
C6 & 0.094 & 14.11 & 0.263 & 0.187 & 0.337 & 0.656 & 0.017 & 0.0038 & 0.0173 & 0.528 \\
\hline
\end{tabular}


A

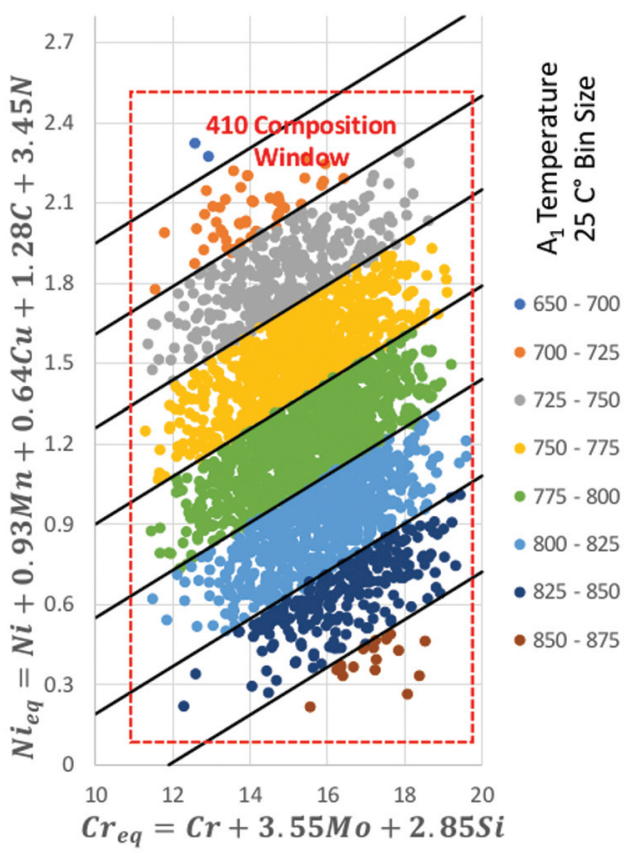

B

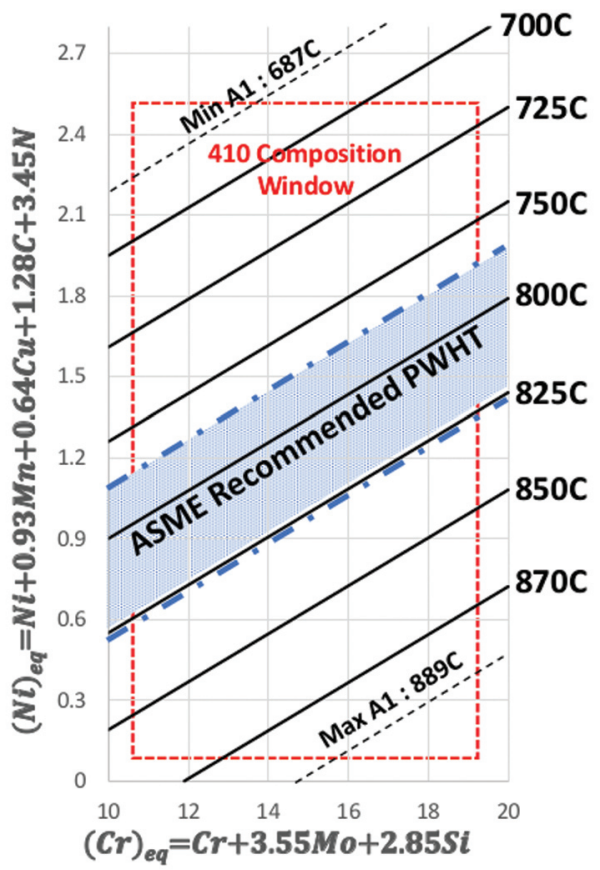

Fig. 6 - A -Distribution of the $A_{1}$ temperature in 2000 random Type 410 steel weld and base metal compositions predicted with the simplified formula (Equation 4); $B-A_{1}$ temperature predictive diagram for Type 410 steel weld and base metals.

\section{Phase Transformation Analysis: Single-Sensor Differential Thermal Analysis}

Single-sensor differential thermal analysis (SS DTA) is a specialized technique for thermal analysis that determines enthalpy variations associated with phase transformations and structural changes in metallic alloys (Refs. 24, 25). The enthalpy variations are identified by comparing recorded thermal histories in materials undergoing phase transformations to calculated reference curves.

In this study, SS DTA could not be used for direct $\mathrm{A}_{1}$ temperature determinations. The Curie transition in Type 410 steel is closely below the onset of the martensite to austenite transformation on heating, partially overlapping the endothermic effect of that transformation. Predicted $\mathrm{A}_{1}$ temperatures were validated by the presence or absence of martensitic transformation on the cooling curves of samples heated correspondingly above and below the predicted $\mathrm{A}_{1}$ temperature of the particular alloy. At normal cooling conditions, the austenite formed above the $\mathrm{A}_{1}$ temperature in Type 410 would transform to martensite. Thus, presence of martensitic transformation on a cooling curve would indicate exceeding the $\mathrm{A}_{1}$ temperature during heating. On the contrary, absence of martensitic transformation on a cooling curve can be accepted as a proof that the $\mathrm{A}_{1}$ temperature was not exceeded.

Using a light radiation furnace (Fig. 2), test samples were heated to temperatures below or above the predicted $\mathrm{A}_{1}$ with a heating rate of $20^{\circ} \mathrm{C} / \mathrm{min}$ temperature, held for $30 \mathrm{~min}$, and free cooled. Thermal histories in the test samples were measured with a Type $\mathrm{K}$ thermocouple, recorded using fast sampling rate data acquisition system, and processed with SS DTA to identify potential on-cooling martensitic trans- formation. Using fresh samples, this procedure was performed repeatedly until the minimum PWHT temperature that resulted in martensitic transformation on cooling in each of the tested alloys was determined within a range of $\pm 10^{\circ} \mathrm{C}$ of the predicted $\mathrm{A}_{1}$ temperature.

\section{Phase Transformation Analysis: Dilatometry}

Dilatometry is a technique for thermomechanical analysis that determines volume changes associated with phase transformations. In this study, dilatometry was performed using the Gleeble ${ }^{\mathrm{TM}}$ thermomechanical simulator with a set of low-force jaws. The latter allows avoiding thermal strain buildup that would be caused by restricted longitudinal expansion and contraction during heating and cooling. This provides conditions for more accurate measurement of the lateral expansion and contraction in test samples caused by phase transformations. The dilatometry experimental setup in the Gleeble ${ }^{\mathrm{TM}}$ is shown in Fig. 3.

The $A_{1}$ temperatures in test samples were determined following the ASTM A1033-10 procedure that involves dilatometry analyses at a heating rate of $28^{\circ} \mathrm{C} / \mathrm{h}$ through the anticipated $\mathrm{A}_{1}-\mathrm{A}_{3}$ intercritical temperature range (Ref. 26). The $A_{1}$ temperature was determined as the starting point of negative volume change on the heating portion of the dilation vs. temperature curve, which represents the starting point of martensite to austenite transformation.

\section{Comparison to Published Experimental Results}

The developed predictive formula for $\mathrm{A}_{1}$ temperature in Type 410 steel weld and base metals was also validated through comparison with experimentally generated data for 


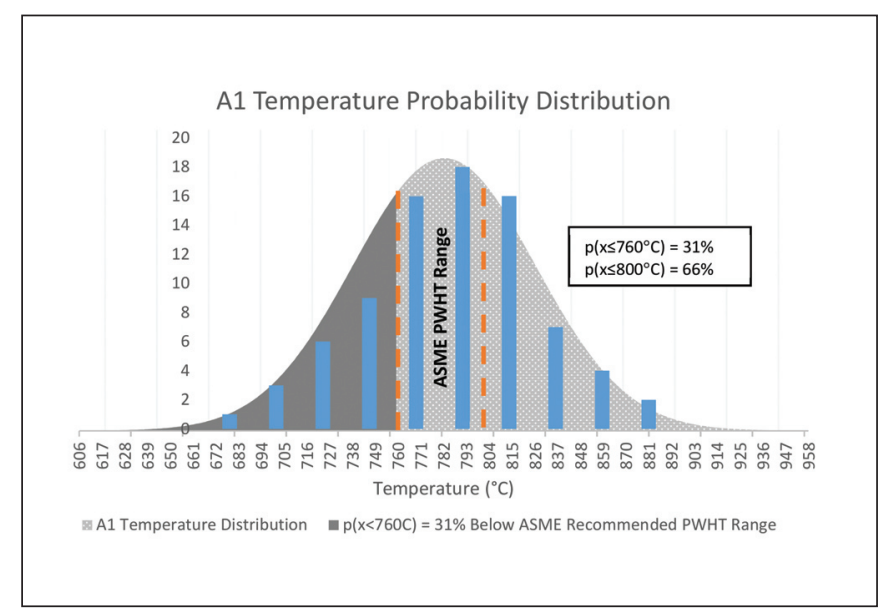

Fig. 7 - Statistical distribution of the $A_{1}$ temperature in Type 410 steel weld and base metals predicted with the modelbased DoE. Probability for exceeding the $A_{1}$ temperature during $\mathrm{PWHT}$ in the ASME-specified temperature range: at $760^{\circ} \mathrm{C}$, $31 \%$; at $800^{\circ} \mathrm{C}, 66 \%$.

$12 \%$ chromium stainless steels published by Ricket et al. (Ref. 18). The chemical compositions of nine alloys tested in that study (Table 4) are within the compositional range of the model-based DoE (see Table 1 ). The $\mathrm{A}_{1}$ temperatures were determined by identification of the lowest PWHT temperature that resulted in higher hardness compared to fully tempered microstructure. The authors noted that the actual $\mathrm{A}_{1}$ temperature could be lower than the one determined using their experimental approach. The latter is similar to the SS DTA approach applied in the presented study.

\section{Results}

\section{$A_{1}$ Temperature Predictions}

An example of equilibrium phase fraction vs. temperature diagram generated using ThermoCalc ${ }^{\mathrm{TM}}$ within the model-based DoE that shows predicted $A_{1}$ and $A_{3}$ temperatures is presented in Fig. 1 . The predicted $A_{1}$ and $A_{3}$ temperatures in all 82 model alloys within the compositional range of Type 410 steel weld and base metals are summarized in Table 2 . The predicted $A_{1}$ temperatures vary in a range of

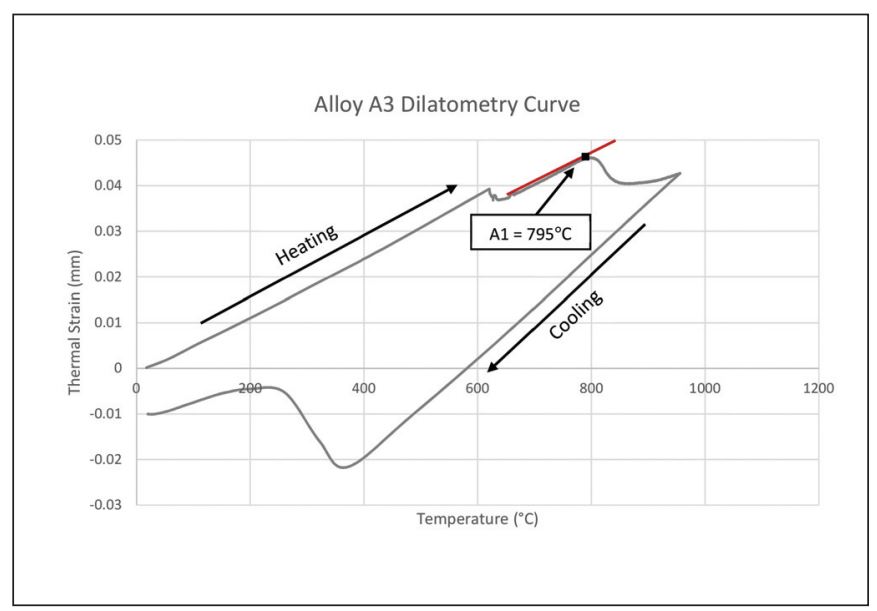

Fig. 8 - Dilatometry curve used for determination of the $A_{l}$ temperature in Alloy A3 following the ASTM 1033-10 procedure.

$202^{\circ}$ from $687^{\circ}$ to $889^{\circ} \mathrm{C}$. The predicted $\mathrm{A}_{3}$ temperatures vary in a range of $215^{\circ}$ from $799^{\circ}$ to $1014^{\circ} \mathrm{C}$.

The developed predictive formulas for the $A_{1}$ and $A_{3}$ temperatures in Type 410 steel weld and base metals are given in Equations 2 and 3 . The $\mathrm{A}_{1}$ temperature predictions for the 82 theoretical compositions made with Equation 2 had a linear relationship ( $\mathrm{R}^{2}$ value) of $99.5 \%$, with the corresponding $\mathrm{A}_{1}$ temperatures generated using ThermoCalc ${ }^{\mathrm{TM}}$. A simplified version on the $A_{1}$ temperature predictive formula that excludes the interaction terms is given in Equation 4. Compared to $\mathrm{A}_{1}$ temperatures generated using ThermoCalc ${ }^{\mathrm{TM}}$, the simplified predictive formula provides an $\mathrm{R}^{2}$ value of $97.81 \%$ along with a standard deviation of 6.5 . The austenite and ferrite promoting elements in Equation 4 were used to establish nickel $\left(\mathrm{Ni}_{\mathrm{Eq}}\right)$ and chromium $\left(\mathrm{Cr}_{\mathrm{Eq}}\right)$ equivalents for Type 410 steel weld and base metals (Equations 5, 6).

$$
\begin{aligned}
& A_{1}=712.54+211.1 \mathrm{C}+10.83 \mathrm{Cr}-15.77 \mathrm{Ni}+14.73 \mathrm{Mo} \\
& +19.07 \mathrm{Si}-55.06 \mathrm{Mn}-5.26 \mathrm{Cu}-281.0 \mathrm{~N}+10918 \mathrm{~N}^{2} \\
& -22.71 \mathrm{C} \times \mathrm{Cr}+35.3 \mathrm{C} \times \mathrm{Ni}-97.7 \mathrm{C} \times \mathrm{Mo}-3.87 \mathrm{Cr} \times \mathrm{Ni} \\
& +1.97 \mathrm{Cr} \times \mathrm{Mo}-2.55 \mathrm{Cr} \times \mathrm{Cu}-43.8 \mathrm{Cr} \times \mathrm{N}-12.12 \mathrm{Ni} \times \mathrm{Mo} \\
& -10.20 \mathrm{Ni} \times \mathrm{Mn}-11.21 \mathrm{Ni} \times \mathrm{Cu}+189.2 \mathrm{Ni} \times \mathrm{N}+3.50 \mathrm{Mo} \\
& \times \mathrm{Si}-9.54 \mathrm{Mo}-\mathrm{Mn}-130.3 \mathrm{Mo} \times \mathrm{N}-5.0 \mathrm{Si} \times \mathrm{Cu}-12.19 \mathrm{Mn} \\
& \times \mathrm{Cu}+81.6 \mathrm{Mn} \times \mathrm{N}+201.1 \mathrm{Cu} \times \mathrm{N}
\end{aligned}
$$

Table 4-Chemical Composition (wt-\%) of Alloys Tested by Rickett et al. (Ref. 17) and Reported $A_{1}$ Temperatures

\begin{tabular}{lccccccccccc} 
& $\mathrm{C}$ & $\mathrm{Cr}$ & $\mathrm{Ni}$ & $\mathrm{Mo}$ & $\mathrm{Mn}$ & $\mathrm{Si}$ & $\mathrm{P}$ & $\mathrm{S}$ & $\mathrm{N}$ & Reported $\mathrm{A}_{1}(\mathrm{C})$ \\
E1 & 0.08 & 11.28 & 0.35 & 0.05 & 0.43 & 0.22 & 0.013 & 0.01 & 0.033 & 766 \\
E2 & 0.11 & 12.18 & 0.16 & 0.02 & 0.44 & 0.37 & 0.014 & 0.01 & 0.033 & 799 \\
E3 & 0.11 & 13.24 & 0.15 & 0.02 & 0.62 & 0.31 & 0.013 & 0.013 & 0.019 & 796 \\
E4 & 0.055 & 12.46 & 0.12 & 0.02 & 0.35 & 0.26 & 0.016 & 0.016 & 0.037 & 804 \\
E5 & 0.14 & 12.54 & 0.22 & 0.03 & 0.49 & 0.17 & 0.024 & 0.019 & 0.047 & 785 \\
E6* & 0.09 & 12.28 & 0.32 & 0.4 & 0.6 & 0.29 & 0.025 & 0.342 & - & 793 \\
E7 & 0.08 & 11.94 & 0.44 & 0.53 & 0.38 & 0.16 & 0.02 & 0.008 & 0.046 & 766 \\
E8 & 0.016 & 12.12 & 0.12 & 0.01 & 0.84 & 0.98 & 0.008 & 0.025 & 0.036 & 804 \\
E9 & 0.016 & 11.93 & 0.2 & 0.01 & 0.85 & 0.96 & 0.011 & 0.025 & 0.046 & 796 \\
\hline
\end{tabular}

*Free machining heats with a high $\mathrm{S}$ content. 

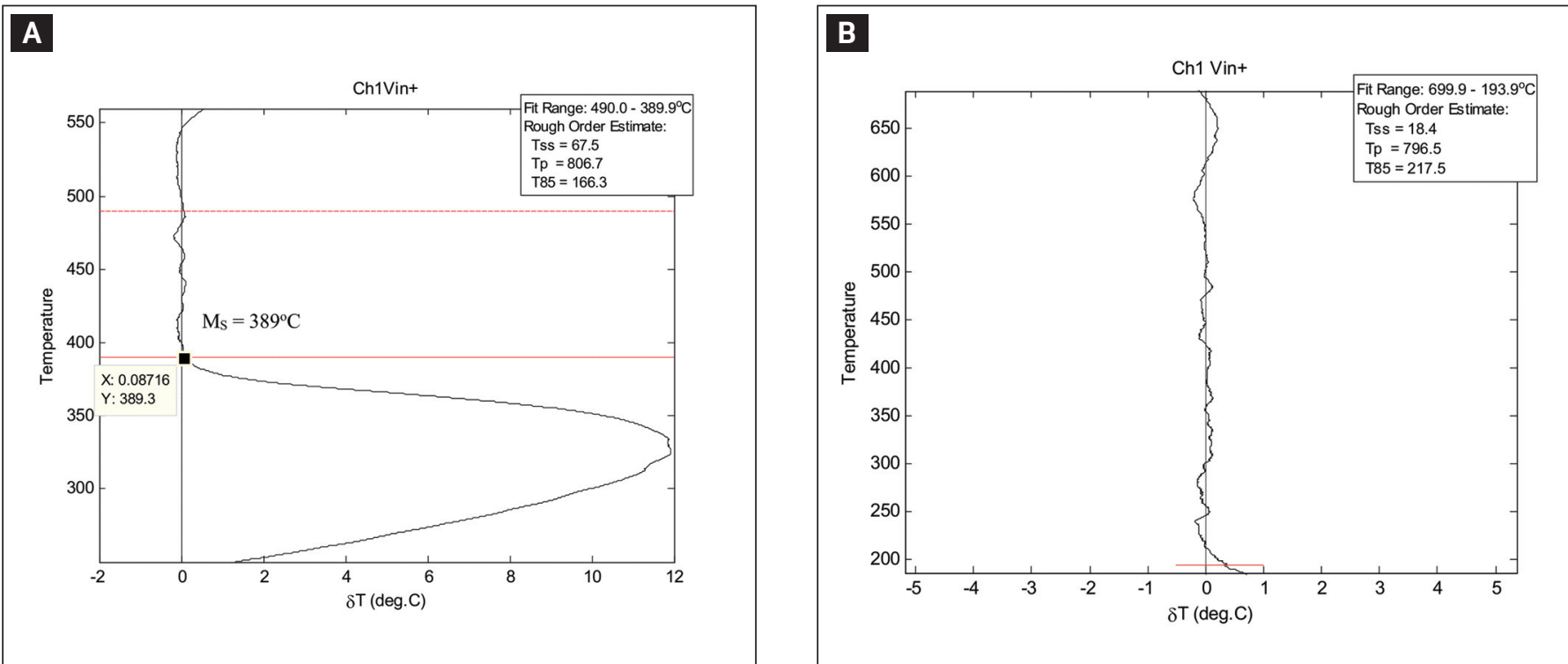

Fig. 9 - SS DTA curves on cooling from PWHT in Alloy A2: A - Exothermic effect of martensitic transformation after PWHT at $809^{\circ} \mathrm{C}$ (above the predicted $A_{l}$ temperature); $B$ - absence of martensitic transformation after PWHT at $797^{\circ} \mathrm{C}$ (at the predicted $A_{l}$ temperature).

$$
\begin{aligned}
& A_{3}=569.9+45 C+31.60 C r-64.11 N i+54.93 M o+22.15 S i \\
& -49.00 M n-50.54 C u-699 N+8432 C^{2}-124.2 C \times C r \\
& +455.4 C \times N i-146.1 C \times M o-128.3 C \times S i+272.9 C \times M n \\
& +411.3 C \times C u+399 M o \times N+385 M n \times N
\end{aligned}
$$

$A_{1}=772.66+6.5 \mathrm{Cr}+20.91 \mathrm{Mo}+18.5 \mathrm{Si}-90.5 \mathrm{C}-70.4 \mathrm{Ni}$

$-65.4 \mathrm{Mn}-45.3 \mathrm{Cu}-242.6 \mathrm{~N}$

$C r_{\mathrm{Eq}}=\mathrm{Cr}+3.55 \mathrm{Mo}+2.85 \mathrm{Si}$

$N i_{\mathrm{Eq}}=N i+0.93 M n+0.64 C u+1.28 C+3.45 N$

The relative effects of alloying elements on the $A_{1}$ temperature were also predicted through the model-based DoE - Fig. 4. The effect of variation of the austenite stabilizing elements within the AWS compositional specification on the $\mathrm{A}_{1}$ temperature was demonstrated using the composition of a commercially available ER410 welding consumable (Alloy A4, see Table 3). The content of most alloying elements in this welding consumable was close to the middle of the AWS compositional specification. The $\mathrm{A}_{1}$ temperature was predicted using Equation 2 with each of the austenite stabilizers at their minimum and maximum values in the AWS compositional range - Fig. 5 .

The $\mathrm{A}_{1}$ temperature distribution diagram for the 2000 random Type 410 compositions plotted using the $\mathrm{Cr}_{\mathrm{Eq}}$ and $\mathrm{Ni}_{\mathrm{Eq}}$ as axes is shown in Fig. 6A. A simplified version of this plot that can be used as an $\mathrm{A}_{1}$ temperature predictive diagram in Type 410 steel base and weld metals is shown in Fig. $6 \mathrm{~B}$. This diagram incorporates the combined ASTM and AWS composition ranges of Type 410 steel weld and base metals, the PWHT temperature range for Type 410 steel welds specified by ASME, and the model-based DoE predicted maximum and minimum $\mathrm{A}_{1}$ temperatures.

A statistical distribution of the $A_{1}$ temperatures in Type 410 steel weld and base metals predicted with the modelbased DoE is shown in Fig. 7. This distribution curve allows es- timating the probability of exceeding the $\mathrm{A}_{1}$ temperature during PWHT within the ASME-specified temperature range.

\section{Experimental Validation}

The developed predictive equation for the $A_{1}$ temperature in Type 410 steel base and weld metal was validated through comparison of predicted and experimentally determined $\mathrm{A}_{1}$ temperatures in the commercially available and custom-made alloys listed in Table 3 . Figure 8 shows a typical dilatometry curve used for determination of the $\mathrm{A}_{1}$ temperatures following the ASTM1033-10 procedure in the tested validation alloys. Typical SS DTA curves of the PWHT cooling cycle in the validation study are shown in Fig. 9. Strong exothermic effects of martensitic transformation were identified when the PWHT was conducted above the corresponding $\mathrm{A}_{1}$ temperatures of the tested alloys - Fig. 9A. PWHT below the $\mathrm{A}_{1}$ temperatures did not result in on-cooling exothermic effects related to martensitic transformation - Fig. 9B.

The presence or absence of fresh martensite in the microstructure of samples subjected to phase transformation analysis with SS DTA after PWHT above and below the $\mathrm{A}_{1}$ temperature was validated by metallurgical characterization. In the as-cast condition, the microstructure of Alloy A3 contained precipitate free packets of fresh martensite and separate grains of delta ferrite retained form the original solidification - Fig. $10 \mathrm{~A}$. PWHT at $787^{\circ} \mathrm{C}$ (below the $\mathrm{A}_{1}$ temperature) resulted in a microstructure of fully tempered martensite composed of finely dispersed precipitates, most probably $\mathrm{M}_{23} \mathrm{C}_{6}$, in a ferritic matrix - Fig. 10B. Separate grains of retained delta ferrite, unchanged during PWHT, are also present in the microstructure. Packets of fresh and partially tempered martensite, identified correspondingly by the absence or presence of precipitates along the packet boundaries and within the packets, were found in the microstructure after PWHT at $806^{\circ} \mathrm{C}$ (above the $\mathrm{A}_{1}$ temperature) Fig. 10C. 


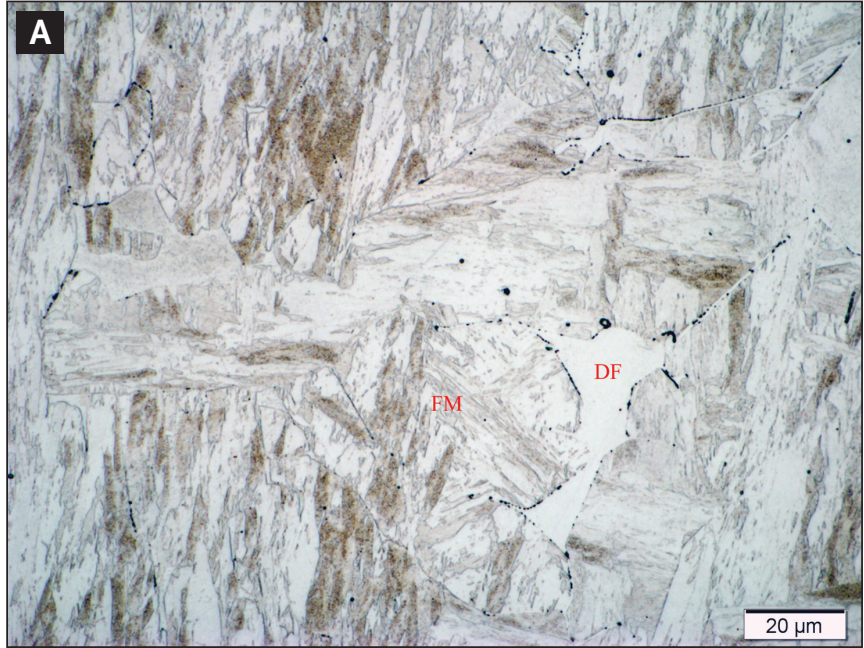

Fig. $10-A-$ Alloy $A 3$ in the as-cast condition: Matrix of fresh martensite (FM) with separate grains of delta ferrite (DF); $B-$ Alloy $\mathrm{A} 3$ after $\mathrm{PWHT}$ at $787^{\circ} \mathrm{C}$ (below the $\mathrm{A}_{1}$ temperature): Matrix of tempered martensite (TM) with a separate grain of retained delta ferrite (DF); $\mathrm{C}-$ Alloy $\mathrm{A3}$ after PWHT at $806^{\circ} \mathrm{C}$ (above the $A_{1}$ temperature): Fresh martensite (FM), partially tempered martensite (PTM), grain of retained delta ferrite (DF).

The $A_{1}$ temperatures in the five commercially available welding consumables (Alloys A1-A5) and six custom-made alloys (C1-C6) determined using dilatometry, and in the nine alloys tested by Rickett et al. (Ref. 18), (Alloys E1-E9), are compared in Table 5 to the corresponding $A_{1}$ values predicted using Equation 2 . The experimentally determined $A_{1}$ temperatures varied between $730^{\circ}$ and $807^{\circ} \mathrm{C}$ and the predicted ones varied in a range from $724^{\circ}$ and $808^{\circ} \mathrm{C}$. The differences (deviations) predicted from experimentally determined $\mathrm{A}_{1}$ temperatures and their average and standard deviations are also shown in Table 5. The average deviation can be used as a measure of accuracy for the developed predictive formula, while the standard deviation can be related to its precision. Plots demonstrating the correlation of $A_{1}$ temperatures predicted using Equation 2 to experimentally determined $\mathrm{A}_{1}$ temperatures are presented in Fig. 11.

The SS DTA validation results of the predicted $A_{1}$ temperatures in Alloys A1 through A5 and B1 through B8 are summarized in Table 6 and Fig. 12. The validation experiments covered a range of predicted $\mathrm{A}_{1}$ temperatures between $748^{\circ}$ and $800^{\circ} \mathrm{C}$. A total of 58 SS DTA validation experiments were performed in ranges of up to $30^{\circ} \mathrm{C}$ below and above individual-predicted $\mathrm{A}_{1}$ temperatures.

\section{Discussion}

Typical heat treatments for welds in martensitic steels include tempering, stress relief, and normalization that can be followed by tempering. The tempering and stress relief heat treatments, known also as PWHT, are usually performed close below the $\mathrm{A}_{1}$ temperature to provide sufficient degree of tempering of the fresh martensite formed in the weld metal and HAZ, and to relieve welding residual stresses. Exceeding the $\mathrm{A}_{1}$ temperature during PWHT would result in formation of fresh martensite on cooling to room tempera-
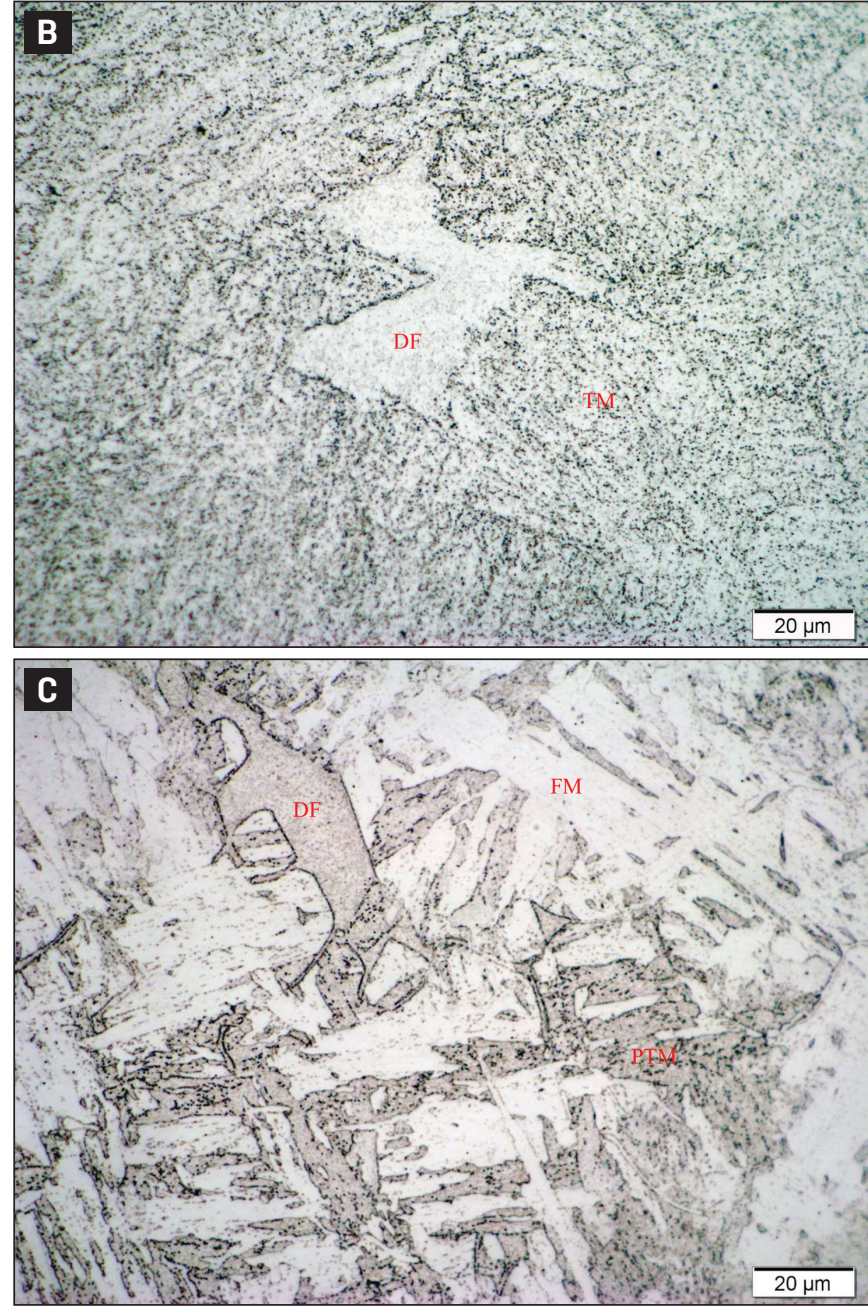

ture and eventually in loss of toughness and/or increased susceptibility to hydrogen-assisted cracking. Normalization that aims at complete recrystallization and carbide dissolution is performed close above the $\mathrm{A}_{3}$ temperature to avoid excessive grain growth. Thus, accurate prediction and/or determination of the equilibrium intercritical temperature range (the $A_{1}$ and $A_{3}$ temperatures) in martensitic steels is critical for the selection of appropriate PWHT and normalization temperatures.

For Type 410 steel welds, ASME B31.3 specifies a PWHT temperature range of $760^{\circ}$ to $800^{\circ} \mathrm{C}$, and ASME Section VIII D1 specifies a minimum PWHT temperature of $760^{\circ} \mathrm{C}$. The conducted model-based DoE study has shown that within the AWS and ASTM specified compositional ranges, the $A_{1}$ temperature in Type 410 steel weld and base metals can vary between $687^{\circ}$ and $889^{\circ} \mathrm{C}$ (see Table 2). Therefore, it is possible to subject welds in Type 410 steel to PWHT significantly above the $A_{1}$ temperature (about $73^{\circ}$ to $113^{\circ} \mathrm{C}$ ) when following the current ASME specifications.

The results of the model-based DoE were subjected to regression analysis aiming at identification of all significant terms and interactions and generation of predictive formulae for the $A_{1}$ and $A_{3}$ temperatures in Type 410 steel weld and base metals. All alloying elements included in the DoE study (see Table 1), including copper and nitrogen, were shown to have a significant effect on the $A_{1}$ and $A_{3}$ tempera- 
Table 5 - Validation: Predicted and Experimentally Determined $A_{1}$ Temperatures in Commercial ( $\left.A_{1}-A_{5}\right)$ and Custom-Made (Cl-C6) Alloys Using Dilatometry, and in Alloys Tested by Rickett et al. (El-E9)

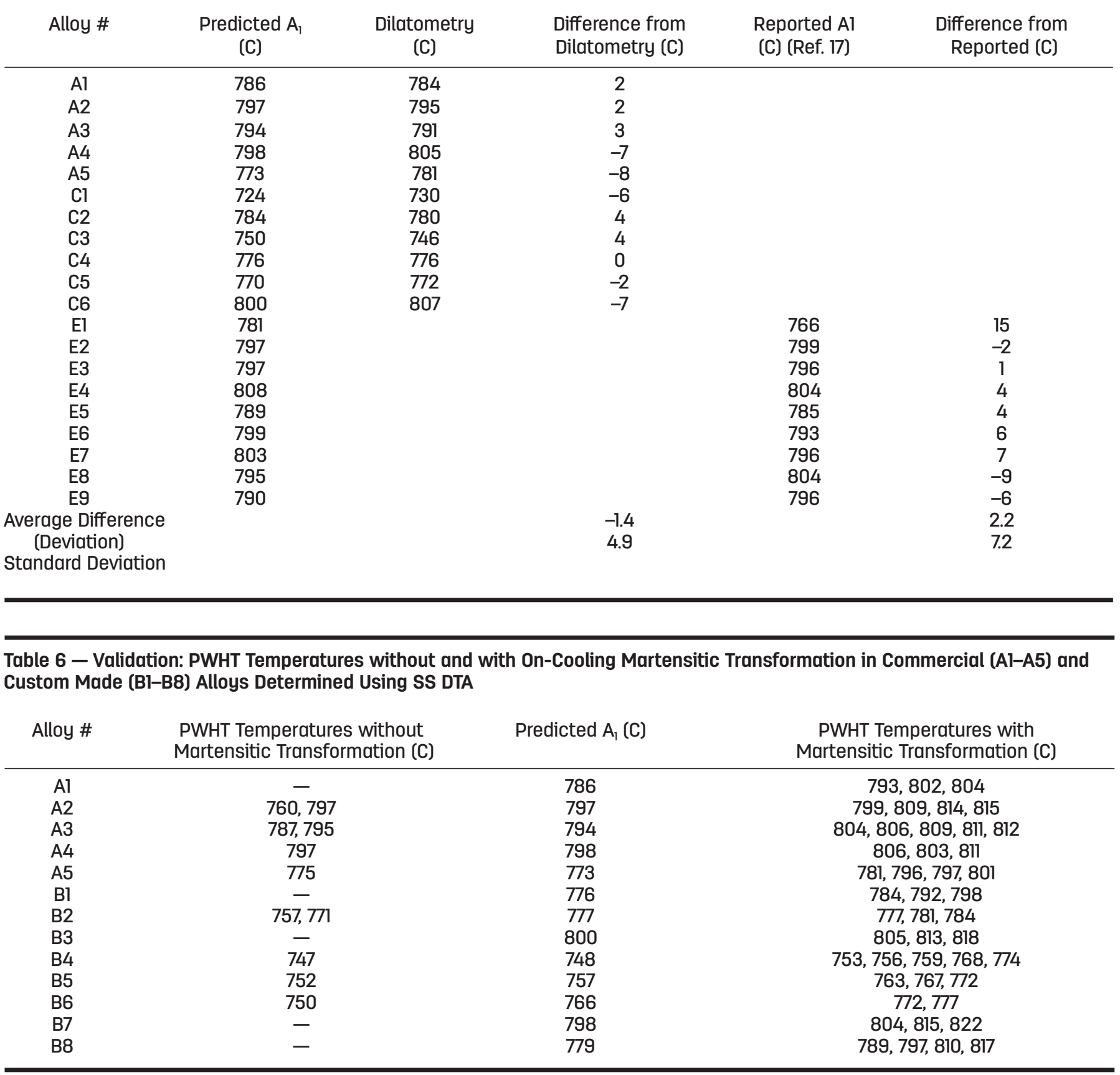

tures $(\mathrm{p}<0.05)$. Most of the first order interactions between the alloying elements also had a significant effect on the $\mathrm{A}_{1}$ temperature (see Equation 2). For the $\mathrm{A}_{3}$ temperature, the effect of first-order interactions of carbon with all alloying elements and of nitrogen with molybdenum and manganese (see Equation 3) was significant.

The relative effects of alloying elements on the $A_{1}$ and $A_{3}$ temperatures were also predicted through the model-based DoE (see Fig. 4). Similar rankings of the effect of manganese, nickel, silicon, and molybdenum on the $\mathrm{A}_{1}$ temperature have been reported by Pickering (Ref. 1). As expected, all austenite stabilizers acted to suppress the $\mathrm{A}_{1}$ temperature, with manganese, nickel, and copper having the strongest effects (see Fig. 4A). All ferrite stabilizers had comparable effects on increasing the $\mathrm{A}_{1}$ temperature. Similarly, the ferrite stabilizers acted on increasing the $A_{3}$ temperature, with chromium and molybdenum having the strongest effects (see Fig. 4B). Carbon, a strong austenite stabilizer, was also predicted to increase the $A_{3}$ temperature. Such behavior could be related to the strong first-order interactions of carbon with other alloying elements, as can be seen in Equation 3, and to the effect of carbides dissolution 


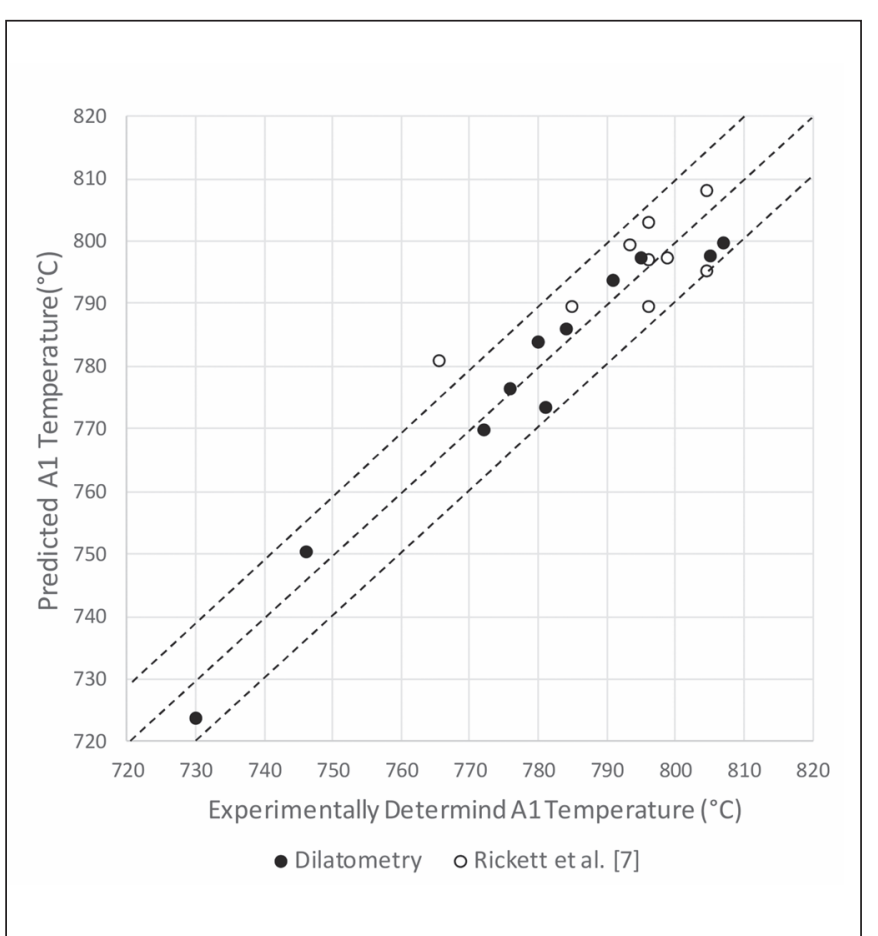

Fig. 11 - Validation of the $A_{1}$ temperature predictive equation: Predicted vs. experimentally determined $A_{1}$ temperatures using dilatometry and published by Rickett et al. (Ref. 7).

on the kinetics of austenite transformation on heating.

One way in which this study expanded past the Type 410 steel and weld metal composition ranges was through inclusion of copper and nitrogen in the DoE. Copper and nitrogen are not included in the ASTM specification, and nitrogen is not included in the AWS specifications. As shown in Fig. 4, both nitrogen and copper were found to be significant factors in suppressing both the $A_{1}$ and $A_{3}$ temperatures. The effect of nitrogen, although small, was found to reduce the $\mathrm{A}_{1}$ temperature by an average of $9^{\circ} \mathrm{C}$ when running all 82 theoretical compositions with and without nitrogen. Even as a small contributor, it should be noted that nitrogen levels included into the DoE ranged from 0 to $0.04 \%$ while higher amounts could possibly lead to greater suppression of the $A_{1}$ and $\mathrm{A}_{3}$ temperatures. Copper, which has a maximum content of 0.75 wt-\% in Type 410 steel welding consumables, was found to be a significant contributor to the suppression of the $\mathrm{A}_{1}$ temperature as the third strongest austenite stabilizing element included into the DoE.

The effect of austenite stabilizing elements on the $A_{1}$ temperature in a commercially available ER410 welding filler metal (Alloy A4, see Table 3) is demonstrated in Fig. 5. Varying the content of manganese, nickel, copper, and carbon within the AWS specification range results in $\mathrm{A}_{1}$ temperature variations of $57^{\circ}, 44^{\circ}, 33^{\circ}$, and $7^{\circ} \mathrm{C}$, correspondingly. Variations in the nitrogen content between 0 and $0.04 \mathrm{wt}-\%$ would result in changes of the $\mathrm{A}_{1}$ temperature in Alloy $\mathrm{A} 4$ within $12^{\circ} \mathrm{C}$. At their maxima, manganese, nickel, and copper would reduce the $\mathrm{A}_{1}$ temperature with about $30^{\circ} \mathrm{C}$ to a level that is very close to the ASME minimum-specified PWHT temperature of $760^{\circ} \mathrm{C}$. Thus, any combination of a maximum content and an elevated content in any two of

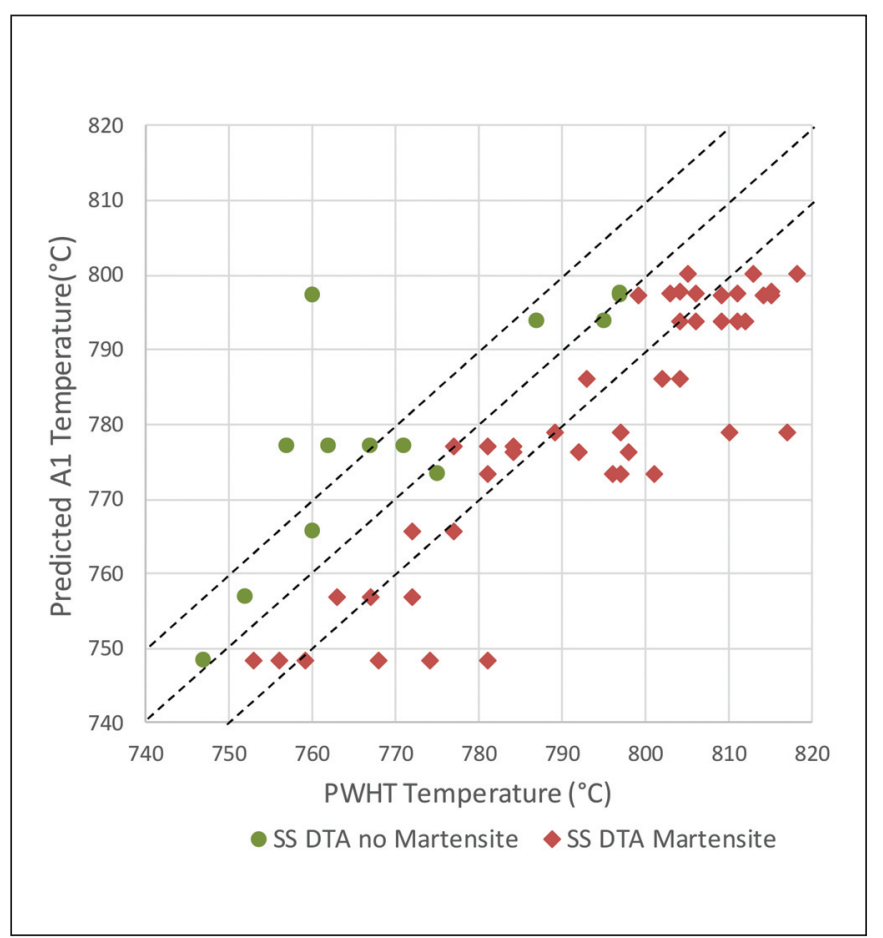

Fig. 12 - Validation of the $A_{1}$ temperature predictive equation using SS DTA: PWHT below and above predicted $A_{1}$ temperatures (without and with on-cooling martensitic transformation).

these three elements would drive the $\mathrm{A}_{1}$ temperature below $760^{\circ} \mathrm{C}$. Elevated nitrogen and carbon content would contribute to additional $\mathrm{A}_{1}$ temperature reduction. On the other hand, at their minimum-specified content, any of the austenite stabilizing elements would drive the $A_{1}$ temperature in Alloy A4 above the ASME maximum-specified PWHT temperature of $800^{\circ} \mathrm{C}$.

The cumulative effects of the ferrite stabilizing $\left(\mathrm{Cr}_{\mathrm{Eq}}\right)$ and the austenite stabilizing alloying elements $\left(\mathrm{Ni}_{\mathrm{Eq}}\right)$ on the $\mathrm{A}_{1}$ temperature are demonstrated in Fig. 6, using the developed chromium and nickel equivalent formulae for Type 410 steel. The diagrams in Fig. 6 were generated using the simplified $\mathrm{A}_{1}$ temperature predictive formula (Equation 4) that has comparable predictive accuracy to the full-predictive formula in Equation 2. The combined ASTM and AWS Type 410 steel weld and base metal composition field is located in a window of approximately $9 \mathrm{Cr}_{\mathrm{Eq}}$ units by $2.5 \mathrm{Ni}_{\mathrm{Eq}}$ units. Variation of the chromium and nickel equivalents within this window would result in $\mathrm{A}_{1}$ temperature variations of $50^{\circ}$ and $190^{\circ} \mathrm{C}$, correspondingly, demonstrating about three times stronger a cumulative effect of the austenite stabilizers on the $A_{1}$ temperature. The $A_{1}$ temperatures in most of the randomly generated 2000 Type 410 steel compositions are concentrated in the temperature range between $725^{\circ}$ and $825^{\circ} \mathrm{C}$, showing high probability in exceeding the $\mathrm{A}_{1}$ temperature when following the PWHT specification of ASME (see Fig. 6A). The diagram in Fig. 6B can be used as a reference tool for development of welding consumables, matching of base metals with welding consumables in terms of $\mathrm{A}_{1}$ temperatures, and selection of PWHT temperatures.

The probability of exceeding the $\mathrm{A}_{1}$ temperature was evaluated by generating a statistical distribution of DoE predict- 
ed $A_{1}$ temperatures (listed in Table 2) within the AWS and ASTM compositional ranges (see Fig. 7). Based on this evaluation, the estimated probability of exceeding the $A_{1}$ temperature and forming fresh, untempered martensite in Type 410 steel welds varies between $31 \%$ and $66 \%$ when PWHT is performed in the ASME specified range of $760^{\circ}$ to $800^{\circ} \mathrm{C}$.

It has to be noted that the chemical composition of commercially available Type 410 steel base metals and welding consumables may not vary throughout the entire ASTM and AWS compositional specifications. For example, the five commercially available welding consumables (Alloys A1-A5 in Table 3 ) used for validation purposes in this study have a composition of well-balanced ferrite and austenite stabilizers. Carbon content close to the upper bound of AWS A5.4 and A5.9 specifications, intermediate content of manganese, and low nickel and copper content are balanced with intermediate content of chromium and silicon, and low molybdenum content. The predicted $A_{1}$ temperatures in these five alloys and the measured $A_{1}$ temperatures in four of them are close below $800^{\circ} \mathrm{C}$ (see Table $5)$, granting low probability of forming fresh martensite during PWHT within the ASME specification range.

Application of the developed $\mathrm{A}_{1}$ temperature predictive tools to an extensive database of chemical compositions in commercially available Type 410 base metals and welding consumables would provide a more realistic estimate for the probability of exceeding the $\mathrm{A}_{1}$ temperature and forming fresh martensite during PWHT of Type 410 steel welds. Such a database can be used for optimization of the AWS and ASTM compositional specifications and of the PWHT temperature range specification of ASME.

The results of this study show that copper and nitrogen have a significant effect on the phase balance and transformations occurring during PWHT in Type 410 steel base and weld metals, and need to be included into the corresponding ASTM and AWS compositional specifications. Further optimization of these specifications could include tightening of the composition ranges of all alloying elements by specifying minimum contents. Currently, the ASTM specification provides low limits only for the carbon and chromium contents, and the AWS specification only for the chromium content.

The developed predictive formula for the $A_{1}$ temperature in Type 410 steel base and weld metals (see Equation 2) was validated through comparison with three independent experimental methods. These included direct $\mathrm{A}_{1}$ temperature determination using dilatometry, as well as indirect identification by the presence or absence of martensitic transformation on cooling from PWHT temperatures determined using SS DTA and hardness comparison to fully tempered microstructure published by Rickett et al. (Ref. 18).

Table 5 and Fig. 11 show a strong correlation of the $A_{1}$ temperatures predicted using Equation 2 with those determined using dilatometry and with the results of Rickett et al. (Ref. 18). The $\mathrm{A}_{1}$ predictions varied between $8^{\circ}$ below and $4^{\circ} \mathrm{C}$ above those determined using dilatometry. An average deviation of $-1.4^{\circ} \mathrm{C}$, calculated as the average of all differences between predicted and experimentally determined $A_{1}$ temperatures, evidences high accuracy of Equation 2 in predicting the $A_{1}$ temperature. The precision of this equation is demonstrated by a standard deviation of $4.9^{\circ} \mathrm{C}$ determined from the differences between predicted and experimentally determined $\mathrm{A}_{1}$ temperatures. The comparison with the $A_{1}$ temperature results published by Rickett et al., showing the average deviation of $2.2^{\circ} \mathrm{C}$ and standard deviation of $7.2^{\circ} \mathrm{C}$, also validates the accuracy and precision of the developed $\mathrm{A}_{1}$ temperature predictive formula.

The results of PWHT experiments instrumented with SS DTA (see Table 6 and Fig. 12) provide additional validation on the $A_{1}$ temperature predictive formula and can be used for estimation of a safety margin of PWHT temperatures. All experiments performed below predicted $\mathrm{A}_{1}$ temperatures did not show on-cooling transformations to martensite. Examples of SS DTA curve without on-cooling exothermic effect related to martensitic transformation in Alloy A2 subjected to PWHT at the predicted $A_{1}$ temperature and of fully tempered microstructure in Alloy A3 subjected to PWHT $7^{\circ} \mathrm{C}$ below the predicted $\mathrm{A}_{1}$ temperature are shown in Figs. 9B and 10B, correspondingly.

Two samples were tested at the predicted $\mathrm{A}_{1}$ temperature, showing absence (Alloy A2) and presence of martensitic transformation (Alloy B2). All alloys subjected to PWHT above the predicted $\mathrm{A}_{1}$ temperature experienced oncooling martensitic transformation, except single experiments in Alloys A3 and A5 performed near the predicted $A_{1}$ temperature. Examples of SS DTA curve showing on-cooling transformation to martensite in Alloy A2 and microstructure containing fresh and partially tempered martensite in Alloy A3, both subjected to PWHT $12^{\circ} \mathrm{C}$ above the predicted $\mathrm{A}_{1}$ temperature, are shown in Figs. 9A and 10C, correspondingly.

The accuracy of dilatometry and SS DTA experiments and related temperature measurements needs to be accounted for when analyzing the validation experiments. An extensive comparative study has shown that both methods have equal accuracy in determination of the starting temperatures in martensite to austenite and austenite to martensite transformations in martensitic steels (Ref. 17). It was also shown that the accuracy of SS DTA is controlled by the accuracy in temperature measurements, and SS DTA was more sensitive than dilatometry in determination of small, volume fraction transformations of austenite to ferrite and bainite. In the current study, special limit of error Type K thermocouples were used. Their accuracy of $0.4 \%$ provides an error range of about $\pm 3^{\circ} \mathrm{C}$ in the studied temperature range between $730^{\circ}$ and $807^{\circ} \mathrm{C}$.

Based on the results from the validation study, it can be concluded that the accuracy of the developed $A_{1}$ temperature predictive equation is within the accuracy of temperature measurements in the validation experiments. These results also provide a general validation of the predictive accuracy of the ThermoCalc ${ }^{\mathrm{TM}}$ software and the TCFE8 steels database, which were utilized in the performed model-based DoE study. The developed predictive tools utilize the alloy chemical composition, therefore the accuracy in $\mathrm{A}_{1}$ temperature predictions would be also controlled by the accuracy in determination of the alloying element's content.

The predictive tools developed in this study can be used in development and/or compositional optimization of 
welding consumables, materials selection, matching of base metals and welding consumables in terms of $A_{1}$ temperatures, and development of PWHT procedures. In cases of significant differences between base and weld metal compositions, the proposed methodology can be applied to predict the $\mathrm{A}_{1}$ temperature in diluted weld metals based on compositions derived from particular levels of dilution. To avoid exceeding the $\mathrm{A}_{1}$ temperature during PWHT, a safety margin of $10^{\circ} \mathrm{C}$ below the predicted $A_{1}$ temperature can be utilized. The latter covers a band of two standard deviations determined in the dilatometry validation experiments and reflects the variation bands in the SS DTA validation and in the comparison to published results (see Tables 5 and 6) - Figs. 11, 12. Additional safety bands below the predicted $A_{1}$ temperature should be considered in relation to the accuracy of temperature measurement and control at particular PWHT conditions.

The approach of model-based DoE demonstrated in this study had also been successfully applied in the development of predictive equations for the $A_{1}$ temperatures in Grade 91 and 92 steel base metals and welding consumables (Refs. 21-23). Such approach can utilize various thermodynamic and kinetic software, and could be applied as a powerful tool for the development and/or optimization of metallic alloys as well as thermal and thermomechanical materials processing.

\section{Conclusions}

Predictive formulas for the $A_{1}$ and $A_{3}$ temperatures in Type 410 steel weld and base metals were developed using the design of experiment approach, based on computational modeling with the thermodynamic software Thermo$\mathrm{Calc}^{\mathrm{TM}}$. Based on the $\mathrm{A}_{1}$ temperature predictive formula, chromium and nickel equivalent equations were established and applied to plot an $\mathrm{A}_{1}$ temperature predictive diagram. The developed $\mathrm{A}_{1}$ temperature predictive tools were validated through phase transformation analysis of commercially available and custom-made alloys within the AWS and ASTM compositional specification ranges, and by comparison to published data. The predictive accuracy of the $\mathrm{A}_{1}$ temperature formula was estimated to be within the error of experimental temperature measurement $\left( \pm 3^{\circ} \mathrm{C}\right)$ and had a standard deviation of $5^{\circ} \mathrm{C}$.

The predicted $A_{1}$ temperature range in Type 410 alloys, within the AWS and ASTM compositional specifications, is between $687^{\circ}$ and $889^{\circ} \mathrm{C}$ and extends below and above the ASME recommended PWHT temperature range of $760^{\circ}$ to $800^{\circ} \mathrm{C}$. The predicted probability of exceeding the $\mathrm{A}_{1}$ temperature during PWHT within the recommended ASME temperature range and formation of fresh martensite in Type 410 steel welds varies between $31 \%$ and $66 \%$. Using phase transformation analysis and metallurgical characterization, it was shown that even small excursions above the $\mathrm{A}_{1}$ temperature during PWHT would result in partial transformation to austenite and on-cooling formation of fresh martensite.

All alloying elements in the Type 410 steel weld and base metal specifications were shown to have a significant effect on the $A_{1}$ and $A_{3}$ temperatures, including copper (not included in the ASTM specification) and nitrogen (not in- cluded in both ASTM and AWS specifications). The austenite stabilizing alloying elements, led by manganese, nickel, and copper, have a stronger effect on the $\mathrm{A}_{1}$ temperature while the ferrite stabilizers, mostly chromium and molybdenum, have a stronger effect on the $\mathrm{A}_{3}$ temperature. Variations in the content of a single austenite stabilizing element within the corresponding specification range may shift the $A_{1}$ temperature of a particular alloy below or above the ASME-specified PWHT temperature range.

The results of this study provide a basis for optimization of the AWS and ASTM compositional specifications for Type 410 steel welding consumables and base metals by inclusion of copper in the ASTM specification and nitrogen in both specifications, and by introduction of lower limits for the content of all alloying elements. Such compositional optimization would significantly shorten the $A_{1}$ temperature range in Type 410 steel weld and base metals and would allow for tightening of the ASME-recommended PWHT temperature range.

The developed $\mathrm{A}_{1}$ and $\mathrm{A}_{3}$ temperature predictive tools can be utilized in development and/or compositional optimization of welding consumables, materials selection, matching of base metals and welding consumables in terms of $\mathrm{A}_{1}$ temperatures, and development of PWHT procedures. The benefit of their implementation is related to meeting the NACE and ASME hardness and toughness requirements for Type 410 steel welds by reducing the probability of formation of fresh martensite in the heat-affected zone and weld metal during PWHT.

The demonstrated approach of model-based DoE can utilize various computational models and software, and can be applied as a powerful tool for the development and/or optimization of metallic alloys as well as thermal and thermomechanical materials processing.

\section{Acknowledgments}

This study was performed within the NSF Manufacturing and Materials Joining Innovation Center ( $\left.\mathrm{Ma}^{2} \mathrm{JIC}\right)$ and was supported by Shell Global Solutions (US) Inc., Houston, Tex.

\section{References}

1. Pickering, F. B. 1978. Physical Metallurgy and Design of Steels. Applied Science Publishers: London, England, pp. 165-182. ISBN13: 978-0853347521

2. Lippold, J. C., and Kotecki, D. J. 2005. Welding Metallurgy and Weldability of Stainless Steels. John Wiley \& Sons: Hoboken, N.J., pp. 56-86. ISBN 978-0-471-47379-4

3. Toshihiro, T., et al. 2012. Quenching and partitioning treatment of a low-carbon martensitic stainless steel. Materials Science and Engineering A: 585-592. DOI: doi.org/10.1016/j.msea.2011.10.125

4. Marshall, A. W., and Farrar, J. C. 2001. Welding of ferritic and martensitic 11-14\% Cr steel. Welding in the World 45(5/6): 32-55.

5. Gooch, T. G., Woollin, P., and Haynes, A. 1999. S99-22 Welding metallurgy of low carbon $13 \%$ chromium martensitic steels. Supermartensitic Stainless Steels '99, Belfian Welding Institute, pp. 188-195.

6. Chakraborty, G., et al. 2015. Study on tempering behaviour of AISI 410 stainless steel. Materials Characterization (100): 81-87. 
DOI: doi.org/10.1016/j.matchar.2014.12.015

7. Arink, G., et al. 1972 . Welding $12 \%$ chromium martensitic stainless steels. Metal Construction and British Welding Journal: 286-290.

8. American Society of Mechanical Engineers. 2016. ASME B31.3, Process Piping. DOI: doi.org/10.1115/b31

9. American Society of Mechanical Engineers. 2015. ASME, BPVC Section VIII-Rules for Construction of Pressure Vessels Division 1. ISBN: 9780791869956

10. NACE International. 2015. ISO 17945/NACE MR01032015, Petroleum, Petrochemical and Natural Gas Industries - Metallic Materials Resistant to Sulfide Stress Cracking in Corrosive Petroleum Refining Environments. ISBN: 1-57590-168-4

11. American Petroleum Institute. 2016. API RP 583, Welding Guidelines for the Chemical, Oil, and Gas Industries.

12. Stone, D. J., Alexandrov, B. T., and Penso, J. A. 2017. Control of retained delta ferrite in Type 410 stainless steel. ASME 2017 Pressure Vessels and Piping Division (PVP) Conference. DOI: doi.org/ 10.1115/pvp2017-65543

13. ASTM International. 2017. ASTM A240/A240M-17, Standard Specification for Chromium and Chromium-Nickel Stainless Steel Plate, Sheet, and Strip for Pressure Vessels and for General Applications. DOI: doi.org/10.1520/A0240_A0240M-17

14. American Welding Society. 2012. AWS A5.4/A5.4M: 2012, Specification for Stainless Steel Electrodes for Shielded Metal Arc Welding. ISBN: 978-0-87171-821-1

15. American Welding Society. 2014. AWS A5.5/A5.5M: 2014, Specification for Low-Alloy Steel Electrodes for Shielded Metal Arc Welding. ISBN: 978-0-87171-850-1

16. Chimbli, S. K. 2016. Failure analysis on 410 stainless square-head bolts failing wedge tensile test. Materials Performance and Characterization 2(1): 440-453. https://doi.org/10.1520/ mpc20130008

17. Nebhnani, M. C., et al. 2002. Failure of a martensitic stainless steel pipe weld in a fossil fuel power plant. Engineering Failure Analysis 9(3): 277-286. DOI: doi.org/10.1016/s1350-6307(01) 00019-x

18. Rickett, R. L., et al. 1952. Isothermal Transformation, Hardening, and Tempering of $12 \%$ Chromium Steel. Trans. ASM 44: 138-175.

19. Iwabuchi, Y., and Sawada, S. 1982. Metallurgical characteristics of a large hydraulic runner casting of type $13 \mathrm{Cr}$-Ni stainless steel. Stainless Steel Castings, ASTM STP756 332-254. DOI: doi.org/10.1520/stp28449s

20. Santella, M. L. 2012. Influence of chemical compositions on lower ferrite-austenite transformation temperatures in $9 \% \mathrm{Cr}$ steels. Journal of Pressure Vessel Technology 134(2): 1-5. DOI: doi.org/10.1115/1.4005399

21. Wang, L. 2010. Development of Predictive Formulae for the $A_{1}$ Temperature in Creep Strength Enhanced Ferritic Steels. Master of Science Thesis, The Ohio State University.

22. Saltzmann, D. R. 2012. Characterization of the Response to Tempering and Development of Predictive Formulae for $\mathrm{A}_{1}$ Temperature in Grade 91 Weld Metal. Master of Science Thesis, The Ohio State University, Columbus, Ohio.

23. Alexandrov, B. T., et al. 2012. Phase transformations in creep strength enhanced ferritic steel welds. Machines, Technologies, Materials 4: 33-36. DOI: doi.org/10.1007/bf03266608

24. Alexandrov, B. T., and Lippold, J. C. 2007. Single sensor differential thermal analysis of phase transformations and structural changes during welding and postweld heat treatment. Welding in the World 51(11, 12): 48-59. DOI: doi.org/10.1007/BF03266608

25. Alexandrov, B. T., and Lippold, J. C. 2005. A New Method for Studying Phase Transformations in High Strength Steel Weld Metal. Trends in Welding Research VII, ASM International, pp. 975-980.

26. ASTM International. 2010. A1033-10, Standard Practice for Quantitative Measurement and Reporting of Hypoeutectoid Carbon and Low-Alloy Steel Phase Transformations. DOI: doi.org/10.1520/ a1033-10

DAVID JOSEPH STONE (stone.457@buckeyemail.osu.edu) is with Norwood Medical, Dayton Ohio. BOIAN T. ALEXANDROV is with The Ohio State University, Columbus, Ohio. JORGE A. PENSO is with Shell Global Solution (US) Inc., Houston, Tex.

\section{Authors: Submit Research Papers Online}

Peer review of research papers is now managed through an online system using Editorial Manager software. Papers can be submitted into the system directly from the Welding Journal page on the AWS website (aws.org) by clicking on "submit papers." You can also access the new site directly at editorialmanager.com/wj/. Follow the instructions to register or log in. This online system streamlines the review process, and makes it easier to submit papers and track their progress. By publishing in the Welding Journal, more than 70,000 members will receive the results of your research.

Additionally, your full paper is posted on the American Welding Society website for FREE access around the globe. There are no page charges, and articles are published in full color. By far, the most people, at the least cost, will recognize your research when you publish in the world-respected Welding Journal. 